\title{
The Intergenerational Transmission of Risk and Trust Attitudes
}

\author{
THOMAS DOHMEN
}

Research Centre for Education and the Labour Market, Maastricht University, Institute for the Study of Labor, and German Institute for Economic Research

\author{
ARMIN FALK \\ University of Bonn, Institute for the Study of Labor, German Institute for Economic Research, \\ and $C E P R$ \\ DAVID HUFFMAN \\ Swarthmore College and Institute for the Study of Labor \\ and \\ UWE SUNDE \\ University of St Gallen, Institute for the Study of Labor, German Institute for Economic \\ Research, and CEPR
}

First version received February 2008; final version accepted January 2011 (Eds.)

\begin{abstract}
Recent theories endogenize the attitude endowments of individuals, assuming that they are shaped by the attitudes of parents and other role models. This paper tests empirically for the relevance of three aspects of the attitude transmission process highlighted in this theoretical literature: (1) transmission of attitudes from parents to children; (2) an impact of prevailing attitudes in the local environment on child attitudes; and (3) positive assortative mating of parents, which enhances the ability of a parent to pass on his or her attitudes to the child. We focus on two fundamentally important attitudes, willingness to take risks and willingness to trust others. We find empirical support for all three aspects, providing an empirical underpinning for the literature. An investigation of underlying mechanisms shows that socialization is important in the transmission process. Various parental characteristics and aspects of family structure are found to strengthen the socialization process, with implications for modeling the socialization production function and for policies focused on affecting children's non-cognitive skills. The paper also provides evidence that the transmission of risk and trust attitudes affects a wide variety of child outcomes, implying a potentially large total effect on children's economic situation.
\end{abstract}

Key words: Risk preferences, Trust, Intergenerational transmission, Cultural economics, Family economics, Assortative mating, Social interactions, SOEP

JEL Codes: D1, D8, J12, J13, J62, Z13

\section{INTRODUCTION}

The usual practice in economics is to treat individual attitude endowments as a black box. Recent theoretical contributions endogenize these endowments by assuming that individuals' attitudes are influenced by the attitudes of their parents or other role models. Attitudes transmitted from 
parents to children may include fundamental preferences, such as risk or time preference, and also crucial beliefs about the world, e.g. priors about the trustworthiness of others. Models sharing the feature of attitude transmission have been used to shed new light on diverse phenomena including the persistence of ethnic differences in the U.S. (Bisin and Verdier, 2000); increasing female labour force participation in the U.S., due to the intergenerational transmission of a change in attitudes towards women and work first triggered by World War II (Fernández et al., 2004); the ascension of the middle class during the British industrial revolution, due to middle-class parents passing on the value of patience to their children (Doepke and Zilibotti, 2005, 2008); the persistence of different fertility and work practices across cultures (Fernández and Fogli, 2005; Guiso, Sapienza and Zingales, 2006; Fernández, 2007); the impact of policy changes (regarding corruption); and historical circumstances decades in the past, such as despotic governments, on current levels of trust and social capital (Hauk and Saez-Marti, 2002; Tabellini, 2005, 2007). These models demonstrate the power of attitude transmission for explaining a diverse set of economic outcomes.

This paper provides evidence on three distinct aspects of the attitude transmission process, which are highlighted by the models in the literature. We test for transmission of attitudes from parents to children using direct measures of attitudes for individuals as well as for their parents. We investigate whether prevailing attitudes in the local environment also have an impact, in addition to the attitudes of parents. We also test for a third aspect of the transmission process, positive assortative mating of parents, on the basis of attitudes to be transmitted to the child; the theory predicts that individuals may strategically engage in positive assortative mating in order to more effectively instill their own attitudes in the child. Our empirical analysis is guided by predictions from the models of Bisin and Verdier (2000) and Bisin, Topa and Verdier (2004), which incorporate all three aspects of the transmission process explicitly.

The analysis focuses on validated survey measures of two particularly important attitudes: willingness to take risks and willingness to trust other people. The former captures an important dimension of individual preferences, while the latter is more related to beliefs, in the context of trustworthiness of others. Transmission of risk attitudes is important for child behavior because almost every important economic decision involves uncertainty. Indeed, risk attitudes have been shown empirically to have a large impact on a wide range of important behaviours and outcomes, including investment in stocks, educational attainment, wealth, home ownership, and patterns of occupational choice. ${ }^{1}$ Trust is similarly important, but in the realm of social interactions, determining the way that an individual approaches other people (Glaeser et al., 2000; Fehr et al., 2003; Kosfeld et al., 2005). Many interactions in life involve vulnerability to defection by others, and trust determines whether an individual cooperates in these situations or enters them at all. The level of trust has also been shown to be heterogeneous across countries and regions and to explain differences in aggregate outcomes such as economic growth, volume of trade, and institutions. ${ }^{2}$ By perpetuating trust differences over time, intergenerational transmission of trust has important ramifications at the aggregate level as well.

Our data are drawn from the 2003 and 2004 waves of the German Socio-Economic Panel Study (SOEP), which included new questions on trust and risk, respectively. Each wave of the SOEP is representative of the German adult population and includes approximately 22,000 individuals. We end up with data on 3751 children for whom we observe the attitudes of both parents. Thus, we also have 3751 parental couples for studying assortative mating of parents.

1. For example, Barsky et al. (1997), Guiso and Paiella (2001), Bonin et al. (2007), Dohmen et al. (2011), and many others.

2. For example, Putnam et al. (1994), Knack and Keefer (1997), Fershtman and Gneezy (2001), Falk and Zehnder (2007), and many others. 
For all individuals in the data, we know the region of residence and can match individuals to an average risk or trust attitude in the region. Notably, the particular survey measures that we use have been validated previously in large-scale field experiments with representative subject pools. These validation studies show that our measure of risk attitudes predicted behaviour in an incentivized lottery experiment measuring risk preference and that the trust measures predict trusting behaviour in a paid trust game. These findings underline the behavioural validity of our measures, addressing an important concern that arises when using survey questions (see, e.g. Camerer and Hogarth, 1999; Glaeser et al., 2000).

Our results are supportive of the attitude transmission approach and indicate that all three aspects play a role in shaping risk attitudes and trust. The first main result is that risk and trust attitudes are strongly positively correlated between parents and children. In other words, parents who are more willing to take risks, or who are more trusting, raise children with similar traits, consistent with a process of intergenerational transmission. These correlations are essentially unchanged when one controls for similarity across generations in personal or environmental characteristics. This includes personality type of the parents and child, showing that transmission of risk and trust attitudes is distinct from transmission of the personality constructs typically studied by psychologists. Additional robustness checks show that the intergenerational correlation is not explained by collaboration on survey answers, similar scale use, reverse causality from children to parents, or by parents and children living in the same geographic region. A second finding is that child attitudes are significantly related to the prevailing attitude in the region, controlling for parental attitudes. This is true for both risk and trust attitudes, and robustness checks show that the result is not driven by children sorting into regions where attitudes are similar to their own. These findings suggest that attitudes in the region play a part in shaping child attitudes, in addition to the parents. The third main finding is a strong positive correlation of attitudes within married couples, for both risk attitudes and trust, consistent with positive assortative mating. We find a similarly large correlation among newly married individuals, indicating that married partners are similar at the outset rather than becoming gradually more similar over time. In combination with the finding that both mothers and fathers matter for child attitudes, this evidence of positive assortative mating is consistent with the predictions of attitude transmission models.

Having provided evidence on the three main aspects of attitude transmission, the paper then delves deeper and provides insights into the mechanisms underlying the transmission process. While it has been argued in psychology that the influence of parents on child personality is solely genetic (Harris, 1995), models of cultural transmission in economics assume that parents are able to socialize the child by exerting effort. Several findings indicate that socialization plays an important role in the transmission process, consistent with the economic models, although this does not rule out that genetics play a role as well. For example, children reproduce the specific variation in attitudes across contexts observed in the parents, which is hard to explain with genetics and indicates that socialization is a rather fine-tuned process. Mothers tend to be more important than fathers for trust transmission, which would not be expected based on genetics but indicates a process of socialization in which parents have unequal impacts on child attitudes. The impact of regional attitudes is another indication of a role for socialization in the transmission process, although in this case socialization by peers. We also investigate the nature of the socialization process in more detail. We identify various parental characteristics and family structures that lead to weaker socialization of the child. For example, the data suggest that parents who are more similar to each other in terms of risk attitudes have a larger impact on the risk attitudes of the child (consistent with a key assumption in Bisin and Verdier, 2000). This could reflect the fact that the child receives a clearer "signal" in the socialization process. These findings are informative for modelling the socialization production function. The determinants of socialization for risk and trust attitudes are in some cases similar but in other cases indicate a 
different process for the two attitudes. The results are potentially informative for policies, which focus on changing non-cognitive skills with early childhood intervention (see Heckman, 2006); they show that fundamental economic attitudes are malleable through socialization and suggest specific factors that may strengthen the tendency for family environment to aid or counteract policy interventions.

The data also shed light on how attitude transmission affects the economic situations of children. While the economic importance of attitude transmission has previously been studied in the context of structural models (e.g. Fernández et al., 2004; Doepke and Zilibotti, 2005, 2008; Fernández and Fogli, 2005; Tabellini, 2005, 2007; Guiso, Sapienza and Zingales, 2006), we investigate the economic relevance of attitude transmission in a different way. We first establish that important economic behaviours such as investment in risky assets, occupational choice, and size of social network are strongly related to our measures of risk and trust attitudes. Using our estimates of the strength of intergenerational transmission in risk and trust attitudes, we then explore how attitude transmission affects child outcomes. We find that the impact on any specific economic behaviour, e.g. occupational choice, is non-trivial, but far from deterministic. Although measurement error in attitudes could bias estimates downward, we conclude that attitude transmission is unlikely to be the sole driver of any specific behaviour. This leaves room for other factors, e.g. institutions, to play an important role in explaining persistence of outcomes across generations. On the other hand, transmission of risk and trust attitudes affects a whole range of outcomes, from holding stocks to occupational choice, to employment status, to social network size, to political affiliation, and is significantly related to outcomes like income, wealth, and education. These findings are likely only the tip of the iceberg as there are many other outcomes that are affected by risk and trust attitudes. Thus, the total effect of attitude transmission seems large. By passing on their risk and trust attitudes, parents fundamentally change the child's whole disposition towards economic decision making, with important ramifications for the child's overall economic situation.

The remainder of the paper is organized as follows. Section 2 describes the data. Section 3 presents results on the intergenerational correlation, Section 4 explores the influence of regional attitudes, and Section 5 investigates assortative mating. Section 6 provides evidence on the importance and nature of socialization in the transmission process. Section 7 discusses the consequences of attitude transmission for child economic situation. Section 8 concludes.

\section{PREDICTIONS AND DATA DESCRIPTION}

We take as our workhorse the seminal model of Bisin and Verdier (2000) and test for the three main aspects of the attitude transmission process highlighted in the model. ${ }^{3}$ Suppose there are two attitudes in the population, $a, b$. The first mechanism for attitude transmission is direct socialization: parents are assumed to exert effort in order to cause the child to have a bundle of attitudes, $i$, similar to their own. A child ends up with attitude bundle $i$ with probability $\tau^{i}$, which can be increased by (costly) parental effort. The motivation of parents is assumed to be altruism towards the child but is "paternalistic" in the sense that parents believe that their own attitudes are the best for the child to have.

With probability $1-\tau^{i}$, socialization efforts of the parents fail, and a second channel for attitude transmission, oblique socialization, becomes relevant such that the child is influenced by a randomly determined individual from the surrounding population. There is still a chance

3. Other models of cultural transmission have typically abstracted away from aspects such as assortative mating of parents, influence of regional attitudes, or both. This partly reflects the different focuses of the analyses for different models. This paper tests for the empirical relevance of all three, which can be informative for future modelling choices. 
that the child nevertheless ends up with the same attitude bundle as the parents, given by the frequency of the bundle $i$ in the population, $q^{i}$. With probability $\left(1-q^{i}\right)$, the child picks a role model with attitude bundle $j \neq i$, which is different from that of the parents.

The model also assumes that the socialization technology of parents is weaker if parents have dissimilar attitudes. Because individuals desire to pass on their own attitudes to a child, this leads to a third aspect of the transmission process: individuals engage in positive assortative mating, actively seeking out a mate with attitude bundle $i$, in order to more effectively socialize the child. ${ }^{4}$ Positive assortative mating is thus a strategy for direct socialization, which exploits the influence of the other parent.

We use data that allow us to observe attitudes of parents and children. With these measures, it is possible to test for the presence of direct and oblique socialization, as well as positive assortative mating. The data come from the German SOEP, a representative panel survey of the resident adult population in Germany (for a detailed description, see Wagner, Burkhauser and Behringer, 1993; Schupp and Wagner, 2002). The initial wave of the survey was conducted in 1984. ${ }^{5}$ For this study, we focus mainly on the 2003 and 2004 waves because these include key attitude questions used in our analysis. Each wave includes roughly 22,000 individuals, from about 12,000 households.

The SOEP conducts a separate in-person interview with each member of a household over the age of 17, in the family's home. A substantial fraction of the interviews, about one quarter, are computer-assisted personal interviews (CAPI), but in general the survey is filled in on paper forms during an oral interview. Importantly, given that we are interested in the correlation or lack of correlation in the responses of family members, interviewers are specifically instructed to administer the survey individually and to take every precaution to ensure that different household members answer independently and are not influenced by each other's responses. If for some reason one household member wants to fill in the paper survey at the same time that the interviewer conducts a personal interview with another household member, the interviewer has to ensure that these two survey respondents are in different rooms. Although the majority of interviews (roughly $80 \%$ in both 2003 and 2004) were completed while the interviewer was present in the household, a small fraction of respondents returned the questionnaire by surface mail, due to severe difficulties in scheduling an appointment with the interviewer. In our analysis, we verify that the results are robust to excluding these mail-in interviews. As a more conservative robustness check, we also verify that the results are sustained regardless of whether children live in the same or separate household from their parents.

The 2004 wave of the SOEP contains a novel battery of questions about the risk attitudes of individuals. One question asks respondents to indicate their willingness to take risks on a 11-point scale. The wording of the general risk question, translated from German, is as follows: "How do you see yourself: Are you generally a person who is fully prepared to take risks or do you try to avoid taking risks? Please tick a box on the scale, where the value 0 means: 'completely unwilling to take risks' and the value 10 means: 'completely willing to take risks' ". 6 The survey also includes five questions that use the same wording and 11-point scale as the

4. More formally, expected utility when direct socialization is possible is given by $W^{i}\left(q^{i}\right)=\max _{\tau^{i}}\left\{\left[\tau^{i}+(1-\right.\right.$ $\left.\left.\left.\tau^{i}\right) q^{i}\right] V^{i i}+\left(1-\tau^{i}\right)\left(1-q^{i}\right) V^{i j}-H\left(\beta \tau^{i}\right)\right\}$, where $i \in\{a, b\}$. The terms $V^{i i}$ and $V i j$ are utilities from successful and unsuccessful socialization, respectively, with $V^{i i}>V^{i j} ; \beta$ is a parameter of the cost function. In the case that the parent has a dissimilar mate, socialization is not possible, and utility is given by $q^{i} V^{i i}+\left(1-q^{i}\right) V^{i j}$. Note that $W^{i}\left(q^{i}\right)>q^{i} V^{i i}+\left(1-q^{i}\right) V^{i j}$ for all $0<q^{i}<1$ and $i \in\{a, b\}$. Thus, mates are complementary, which implies positive assortative mating.

5. The panel was extended to include East Germany in 1990 after reunification. For more details on the SOEP, see www.diw.de/gsoep/.

6. German versions of all risk questions are available online at www.diw.de. 
general risk question but ask about willingness to take risks in specific contexts: car driving, financial matters, sports and leisure, career, and health. A final risk measure is provided by a question that poses respondents with a hypothetical lottery in which they can choose how much of 100,000 Euros to invest and either double or get back only half of their investment, with equal probability. This question differs from the previous risk measures in that it uses a different scale and includes a different context.

In the 2003 wave, the SOEP survey includes three questions about individuals' trust attitudes. These are similar to the standard measures of trust used in other surveys, e.g. the General Social Survey. Subjects were asked to indicate on a four-point scale to what extent they agree or disagree with the following statements: (1) In general, one can trust people. (2) These days you cannot rely on anybody else. (3) When dealing with strangers, it is better to be careful before you trust them. The four answer categories were labelled: strongly agree, agree somewhat, disagree somewhat, strongly disagree.

Transmission of risk and trust attitudes is important if these attitudes affect behaviour, as is typically assumed in economic theory. The behavioural relevance of the particular measures of risk attitudes that we use has been shown empirically in experiments with a representative subject pool. Dohmen et al. (2011) conduct an experiment with 450 individuals in their homes, sampled from all regions of Germany to be representative of the adult population (sampling was done with the same method used to construct the full SOEP sample; see Fowler, 1988). All subjects in the experiment first completed a detailed questionnaire, which included the exact same general risk question asked in the 2004 wave of the SOEP. Subjects then participated in a lottery experiment involving substantial monetary stakes. ${ }^{7}$ The authors find that the questionnaire responses to the general risk question are reliable predictors of actual risk taking behaviour in the lottery experiment.

Fehr et al. (2003) validate the behavioural relevance of the trust measures we use in a field experiment with a representative sample of 429 subjects, sampled using the same procedure as the risk experiment described above. Subjects first completed a detailed questionnaire that contained the same three measures on trust attitudes that were asked in the 2003 wave of the SOEP. Subjects then played a modified version of the trust game developed by Berg, Dickhaut and McCabe (1995), a standard tool for eliciting willingness to trust. ${ }^{8}$ Fehr et al. (2003) summarize an individual's responses to the three survey questions about trust using factor analysis and then show that this combined measure is a significant predictor of the amount that a first-mover actually sends to the other player in the incentive compatible trust game. As discussed in Section 1, similar trust measures to ours have also been shown in previous studies to play an important role in explaining aggregate outcomes such as growth, functioning of institutions, and volume of trade.

Since we want to investigate whether and to what extent trust and risk attitudes are correlated between parents and children, we focus our analysis on respondents whose parents also answered the same survey questions. In total, we have complete information on either trust or risk attitudes

7. In the experiment, subjects had to decide between a lottery in which they could either win 300 Euros with probability $1 / 2$ or receive nothing with probability $1 / 2$ and a series of different safe payment alternatives. The lottery option remained the same across choices, but the alternative safe payment option was increased in steps of 10 Euros up to a maximum of 190 Euros. Subjects were informed in advance that one of their choices would be randomly selected for payment and that one out of seven participants would actually be paid according to the selected choice.

8. In the design, two players, both endowed with 10 Euros, were randomly matched. Player A could then send any amount between 1 and 10 Euros to Player B. The amount that A sent was doubled by the experimenter so that B received twice the amount that A had sent. B could then send money back to A, but this was not enforceable. The experimenter doubled any amount sent by B with the result that A received twice the amount that B had sent. The amount that Player A sends in this game is a measure of trust. 
for 3751 children and both their parents. ${ }^{9}$ We refer to a three-person group consisting of two parents and their child as a parents-child pair in the remainder of the paper.

A noteworthy feature of the data is that they allow the study of children at a wide variety of ages, rather than just teenage children. This is because the SOEP not only interviews adult children living with their parents but also follows children once they are older and have moved out of the parents' home to form a new household. For our sample of 3751 parents-child pairs, $56.9 \%$ live in the same household, while $39.6 \%$ of children in our sample live in different households from both of their parents. Only a small fraction lives in the same household with only one parent. Half of the children in our sample are older than 23 years of age, and the oldest child is 54. On average, children in our sample are 25.3 years old (standard deviation (S.D.) 6.96). Fathers in our sample are on average 54.6 years old (S.D. 8.70) and mothers are on average 51.7 years of age (S.D. 8.3).

Variation in parents' willingness to take risks and trust is a prerequisite for identifying an impact of parents' risk and trust attitudes on children's attitudes. Figure 1 indicates that there is in fact substantial variation for both mothers and fathers. The histograms for willingness to take risks (upper panel) report the fraction of fathers and mothers choosing a given answer on the 11-point scale of the general risk question. The histograms for trust (lower panel) show the distributions of the parental trust measures. These are derived from principal component analysis and combine responses to the three separate measures into a scalar, analogous to the approach taken in Fehr et al. (2003). ${ }^{10}$ We use these trust measures throughout the paper and construct the measure for the child in the same way. Throughout the analysis, we use standardized versions of the risk and trust measures in order to aid comparison of coefficients. Standardization is conducted separately for the child, the mother, and the father, for the sample where the child and both parents all have non-missing attitude responses.

Figure 1 also shows that mothers are less willing to take risks than fathers, in line with the gender effect that Dohmen et al. (2011) find using the entire sample of the 2004 wave. In additional regressions (unreported), we find that other exogenous characteristics are also significantly related to risk and trust attitudes. ${ }^{11}$ Age is associated with significantly lower willingness to take risks $(p<0 \cdot 01)$ and reduced trust $(p<0 \cdot 01)$. Greater height is associated with significantly greater willingness to take risks $(p<0.01)$ and trust $(p<0.05)$. Religion is significantly related to risk attitudes, for instance Catholics are significantly more willing to take risks than some other Christian denominations $(p<0 \cdot 01)$. Growing up in a big city, rather than a small town, is associated with significantly greater willingness to take risks $(p<0 \cdot 10)$ and greater

9. For 3327 children in the 2003 wave, we have complete information on their own answers to the trust questions and both of their parents' answers to these questions. We also have complete information about willingness to take risks for 3331 children from the 2004 wave and both their parents. These samples do not completely coincide because some of the children or their parents that were interviewed in 2003 did not answer the questions about risk attitudes in the 2004 wave. Likewise, in the 2004 wave we do not have information on some subjects' answers to the trust questions in 2003. These are mostly respondents who were not yet interviewed in 2003.

10. We obtain an individual's trust measure by multiplying the standardized answers to the respective trust questions with the loadings of the questions on the principal component. Principal components analysis is preferable to factor analysis as we are interested in capturing and using the essential variation of the responses in regression analysis across parents-child pairs, rather than for detailed analysis of covariance (see also Tabachnick and Fidell, 2001). However, our results are almost identical if we instead use factor analysis for all regressions. We obtain the principal component without rotation. Analysis of eigenvalues suggests that only the principal component exhibits an eigenvalue larger than unity. The factor loadings, which are multiplying the standardized responses to the trust, reliance, and caution questions are $-0.7968,0.8187$, and 0.6377 , respectively, for children, $-0.7819,0.8170$, and 0.6619 , respectively, for fathers, and $-0.7687,0.8113$, and 0.6132 , respectively, for mothers.

11. Estimates are from OLS regressions, with robust standard errors adjusted for clustering at the household level. 

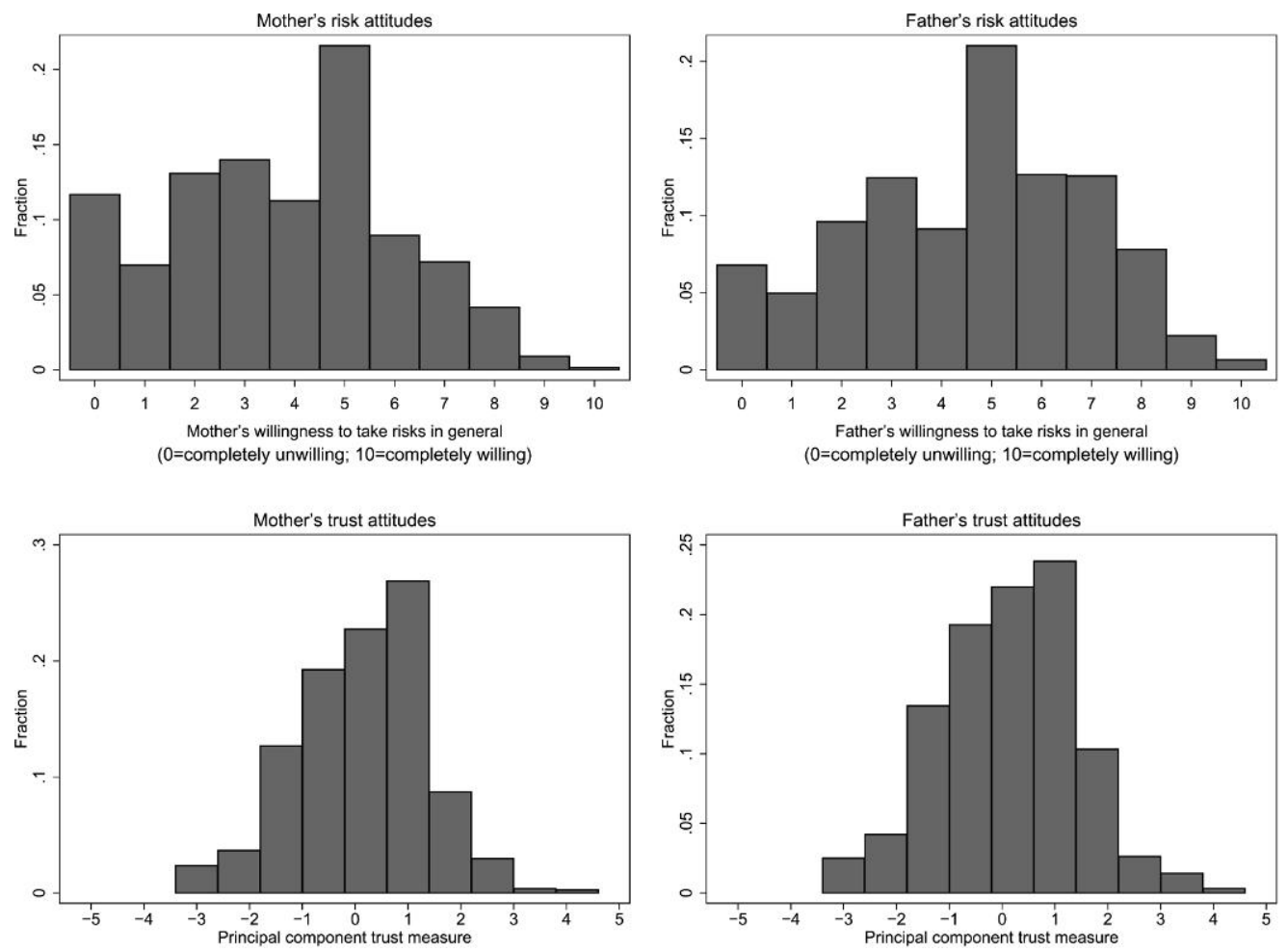

FIGURE 1

Parents' attitudes towards risk and trust. The upper histograms in the figure show the distributions of responses to the question about general risk attitudes for mothers (left histogram) and fathers (right histogram). The bottom histograms in the figure show the distributions of the trust principal component, which combines the information from three separate survey measures of trust, for mothers (left histogram) and fathers (right histogram)

trust ( $p<0 \cdot 01$ ). These results motivate us to control for such exogenous factors in the subsequent analysis where we investigate whether parent and child attitudes are similar even after controlling for similarity in other characteristics that affect attitudes.

\section{INTERGENERATIONAL CORRELATION IN ECONOMIC ATTITUDES}

\subsection{Risk attitudes}

We begin the analysis by assessing whether there is an intergenerational correlation in willingness to take risks. Initially, we focus on the general risk question, and then we assess the robustness of the results to using alternative survey measures.

Figure 2 provides a first look at the relationship between the general risk attitudes of parents and children, as it appears in the raw data. The figure shows children's average willingness to take risks, for given willingness to take risks of their mother (upper left diagram) or their father (upper right diagram). Children's willingness to take risks is clearly positively associated with parents' willingness to take risks. This is illustrated by the positively sloped regression lines in the diagrams, which are based on a weighted regression of children's willingness to take risks on the respective parent's willingness to take risks. The weighting takes into account the frequency 

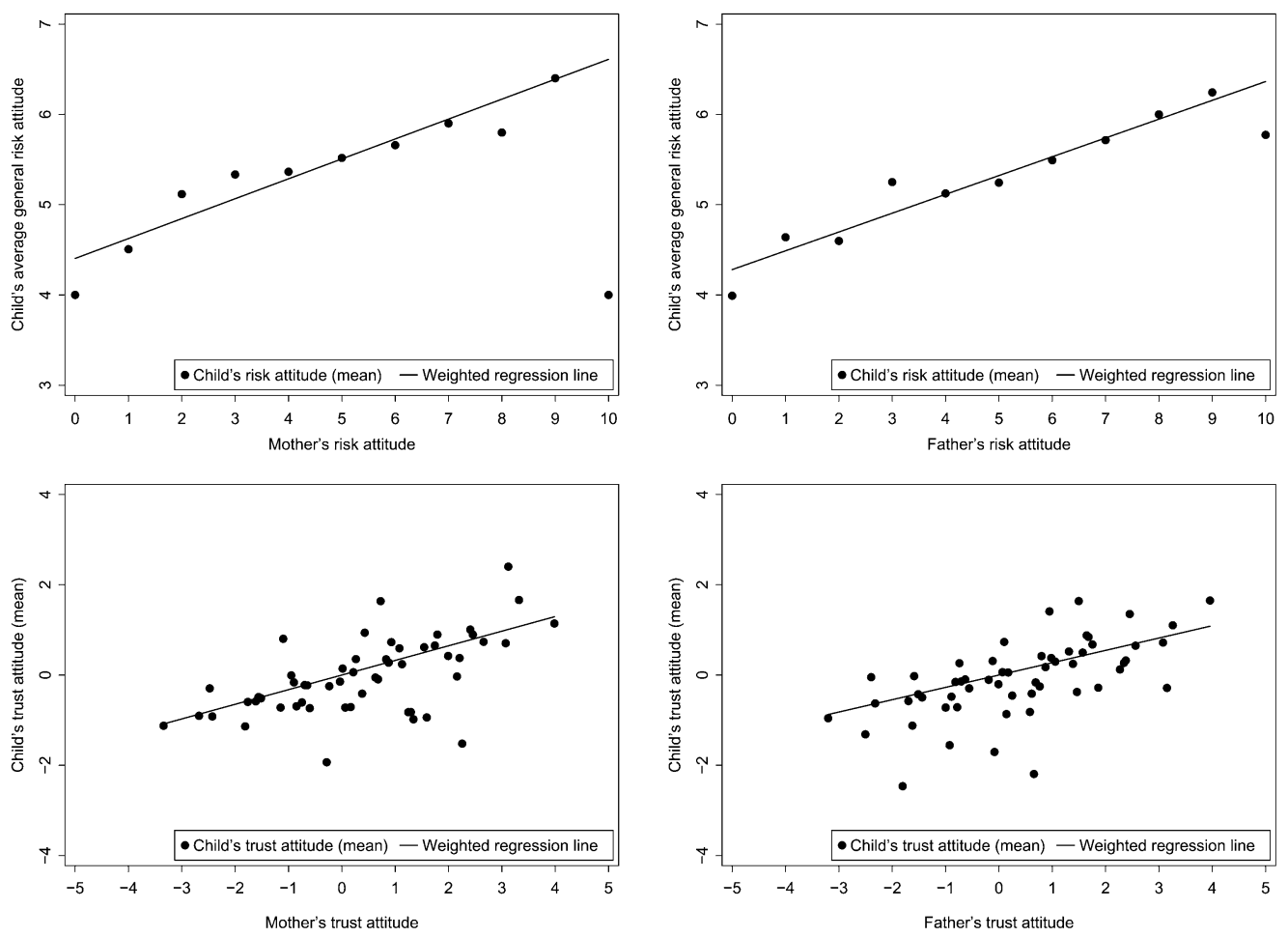

FIGURE 2

Child's attitudes towards risk and trust as a function of parents'. The upper graphs in the figure show children's average self-reported willingness to take risks for a given willingness to take risks of mothers (left diagram) and fathers (right diagram). The bottom graphs in the figure show children's average principal component "trust" for a given principal component "trust" of mothers (left diagram) and fathers (right diagram)

of child-parent pairs with a particular combination of willingness to take risks, i.e. the number of children whose parent states a particular value on the risk scale. ${ }^{12}$

In Table 1, we regress children's standardized answers to the general risk question on the answers of their respective mothers and fathers. We estimate linear regressions, where the dependent variable is the child's general willingness to take risk. ${ }^{13}$ The key explanatory variables are standardized risk attitudes of mothers and fathers. We report robust standard errors, corrected for possible correlation of the error term across individuals from the same household.

Column (1) of Table 1 shows that on average children report a greater willingness to take risks as parents' willingness to take risks increases. Coefficients for the mother and the father are both

12. Note that there is an outlier for mothers choosing a value of 10 on the risk scale. This outlier has little impact on the slope of the weighted regression line, however, because there are very few mothers in this category (see Figure 1, upper left panel).

13. The results are robust to using other estimation techniques. We have alternatively conducted all estimations with interval regression techniques that correct for censoring of the dependent variable. In this case, we find virtually identical results, which are available upon request. We also used a binary measure, indicating willingness to take risks if individuals responded a value greater than five on the scale from 0 to 10 . All results are essentially the same if we use the binary measure instead of the full scale. 
TABLE 1

The relationship between children's and parents' attitudes

\begin{tabular}{|c|c|c|c|c|c|c|c|c|}
\hline \multirow[b]{2}{*}{ Dependent variable } & \multicolumn{4}{|c|}{$\begin{array}{l}\text { Child's willingness } \\
\text { to take risks in general }\end{array}$} & \multicolumn{4}{|c|}{$\begin{array}{l}\text { Child's trust } \\
\text { (principal component) }\end{array}$} \\
\hline & (1) & (2) & (3) & (4) & (5) & (6) & (7) & (8) \\
\hline Mother's willingness to & $0 \cdot 166^{* * *}$ & $0 \cdot 154^{* * *}$ & $0 \cdot 149^{* * *}$ & $0 \cdot 141^{* * *}$ & & & & $-0 \cdot 015$ \\
\hline take risks in general & {$[0 \cdot 019]$} & {$[0 \cdot 019]$} & {$[0 \cdot 022]$} & {$[0 \cdot 024]$} & & & & {$[0 \cdot 022]$} \\
\hline Father's willingness to & $0 \cdot 157^{* * *}$ & $0 \cdot 143^{* * *}$ & $0 \cdot 153^{* * *}$ & $0 \cdot 173^{* * *}$ & & & & -0.035 \\
\hline take risks in general & {$[0 \cdot 020]$} & {$[0 \cdot 020]$} & {$[0 \cdot 023]$} & {$[0 \cdot 025]$} & & & & {$[0.023]$} \\
\hline Trust: mother & & & & $\begin{array}{c}-0.067^{* * *} \\
{[0.025]}\end{array}$ & $\begin{array}{l}0 \cdot 239^{* * *} \\
{[0 \cdot 020]}\end{array}$ & $\begin{array}{l}0 \cdot 235^{* * *} \\
{[0 \cdot 020]}\end{array}$ & $\begin{array}{l}0 \cdot 200^{* * *} \\
{[0 \cdot 024]}\end{array}$ & $\begin{array}{l}0.202^{* * *} \\
{[0.024]}\end{array}$ \\
\hline Trust: father & & & & $\begin{array}{c}-0.031 \\
{[0.025]}\end{array}$ & $\begin{array}{l}0 \cdot 160^{* * *} \\
{[0 \cdot 020]}\end{array}$ & $\begin{array}{l}0.157^{* * *} \\
{[0 \cdot 020]}\end{array}$ & $\begin{array}{l}0 \cdot 140^{* * *} \\
{[0 \cdot 024]}\end{array}$ & $\begin{array}{l}0.145^{* * *} \\
{[0.024]}\end{array}$ \\
\hline $\begin{array}{l}\text { Child's willingness to } \\
\text { take risks in general }\end{array}$ & & & & & & & & $\begin{array}{l}0 \cdot 044^{* *} \\
{[0 \cdot 022]}\end{array}$ \\
\hline Trust: child & & & & $\begin{array}{l}0 \cdot 046^{* *} \\
{[0 \cdot 023]}\end{array}$ & & & & \\
\hline 1 if female & & $\begin{array}{l}-0 \cdot 229^{* * *} \\
{[0 \cdot 051]}\end{array}$ & $\begin{array}{c}-0.215^{* * *} \\
{[0.055]}\end{array}$ & $\begin{array}{c}-0.254^{* * *} \\
{[0 \cdot 060]}\end{array}$ & & $\begin{array}{c}0.000 \\
{[0 \cdot 052]}\end{array}$ & $\begin{array}{r}-0.038 \\
{[0 \cdot 060]}\end{array}$ & $\begin{array}{r}-0 \cdot 017 \\
{[0 \cdot 060]}\end{array}$ \\
\hline Age of child (years) & & $\begin{array}{c}-0 \cdot 017^{* * *} \\
{[0 \cdot 004]}\end{array}$ & $\begin{array}{l}-0.020^{* * *} \\
{[0.005]}\end{array}$ & $\begin{array}{c}-0.016^{* * *} \\
{[0.005]}\end{array}$ & & $\begin{array}{c}-0 \cdot 014^{* * *} \\
{[0 \cdot 004]}\end{array}$ & $\begin{array}{r}-0.009^{*} \\
{[0.005]}\end{array}$ & $\begin{array}{r}-0.009^{*} \\
{[0.005]}\end{array}$ \\
\hline Height of child $(\mathrm{cm})$ & & $\begin{array}{l}0.009^{* * *} \\
{[0 \cdot 003]}\end{array}$ & $\begin{array}{l}0.009^{* * *} \\
{[0.003]}\end{array}$ & $\begin{array}{c}0.008^{* *} \\
{[0.004]}\end{array}$ & & $\begin{array}{c}0.003 \\
{[0.003]}\end{array}$ & $\begin{array}{c}0.001 \\
{[0.003]}\end{array}$ & $\begin{array}{c}0.001 \\
{[0.003]}\end{array}$ \\
\hline Age of mother (years) & & $\begin{array}{c}0 \cdot 010^{* *} \\
{[0 \cdot 005]}\end{array}$ & $\begin{array}{l}0 \cdot 015^{* * *} \\
{[0 \cdot 006]}\end{array}$ & $\begin{array}{c}0.015^{* *} \\
{[0.006]}\end{array}$ & & $\begin{array}{c}0.009^{*} \\
{[0.005]}\end{array}$ & $\begin{array}{l}0 \cdot 013^{* *} \\
{[0 \cdot 006]}\end{array}$ & $\begin{array}{c}0.012^{*} \\
{[0.006]}\end{array}$ \\
\hline Age of father (years) & & $\begin{array}{l}-0 \cdot 007 \\
{[0 \cdot 004]}\end{array}$ & $\begin{array}{c}-0.012^{* *} \\
{[0 \cdot 005]}\end{array}$ & $\begin{array}{c}-0.015^{* *} \\
{[0.006]}\end{array}$ & & $\begin{array}{c}0.005 \\
{[0 \cdot 005]}\end{array}$ & $\begin{array}{c}-0.000 \\
{[0.006]}\end{array}$ & $\begin{array}{c}-0.000 \\
{[0.006]}\end{array}$ \\
\hline Height of mother $(\mathrm{cm})$ & & $\begin{array}{r}-0.002 \\
{[0.003]}\end{array}$ & $\begin{array}{c}-0.002 \\
{[0.004]}\end{array}$ & $\begin{array}{c}-0.002 \\
{[0.004]}\end{array}$ & & $\begin{array}{r}-0.000 \\
{[0.003]}\end{array}$ & $\begin{array}{c}-0.003 \\
{[0.004]}\end{array}$ & $\begin{array}{c}-0.003 \\
{[0.004]}\end{array}$ \\
\hline Height of father $(\mathrm{cm})$ & & $\begin{array}{r}-0.003 \\
{[0.003]}\end{array}$ & $\begin{array}{r}-0.003 \\
{[0.003]}\end{array}$ & $\begin{array}{r}-0.002 \\
{[0.003]}\end{array}$ & & $\begin{array}{c}0.004 \\
{[0.003]}\end{array}$ & $\begin{array}{c}0.001 \\
{[0 \cdot 003]}\end{array}$ & $\begin{array}{c}0.001 \\
{[0.003]}\end{array}$ \\
\hline Constant & $\begin{array}{c}0.001 \\
{[0 \cdot 017]}\end{array}$ & $\begin{array}{c}-0.461 \\
{[0.616]}\end{array}$ & $\begin{array}{r}-0.729 \\
{[0.759]}\end{array}$ & $\begin{array}{r}-0.596 \\
{[0.803]}\end{array}$ & $\begin{array}{c}0 \cdot 001 \\
{[0 \cdot 017]}\end{array}$ & $\begin{array}{c}-1.496^{* *} \\
{[0.640]}\end{array}$ & $\begin{array}{c}0.354 \\
{[0.824]}\end{array}$ & $\begin{array}{c}0.325 \\
{[0.830]}\end{array}$ \\
\hline Additional controls & No & No & Yes & Yes & No & No & Yes & Yes \\
\hline Observations & 3337 & 3333 & 2985 & 2583 & 3301 & 3250 & 2601 & 2583 \\
\hline $\mathrm{R}^{2}$ & $0 \cdot 072$ & $0 \cdot 112$ & $0 \cdot 208$ & $0 \cdot 228$ & $0 \cdot 119$ & $0 \cdot 128$ & $0 \cdot 258$ & $0 \cdot 261$ \\
\hline
\end{tabular}

Notes: The dependent variable in Columns (1)-(4) measures general willingness to take risks on a 11-point scale from 0 (completely unwilling to take risks) to 10 (completely willing to take risks). The dependent variable in Columns (5)-(8) is trust measured as the principal component obtained from agreement with three statements regarding trust (general trust, reliance on others, need for caution in dealing with strangers) measured on a four-point scale. All dependent variables are standardized. Explanatory risk variables are also measured on the 11-point scale; explanatory trust variables are measured as principal components and are also standardized. Coefficients in all columns are OLS estimates. Robust standard errors in brackets allow for clustering at the household level; ***,**, and * indicate significance at $1 \%, 5 \%$, and $10 \%$ level, respectively. Additional controls include years of schooling of child and child's father and mother; corresponding indicator variables for missing schooling information; indicator variables for characteristics of the residence of youth before the age of 16, for child and parents (big city, city, countryside, missing; the reference category is small town); indicator variables for religion of child and parents (catholic, protestant, other non-Christian, no religious affiliation, missing religion; the reference category is other Christian), gross annual household income for child, child's mother and father, subjective health status of child, and child's mother and father (five response categories), and fixed effects for region (Raumordnungsregion) and 17 nationality-ethnicity dummies (reference category is German). All religion information is obtained from the 2003 wave of the SOEP. 
highly significant and are of comparable size, indicating that child attitudes are strongly related to attitudes of both parents. The coefficients on parents' risk attitudes are sizable compared to other important variables. The marginal effect

We also estimated the same regression as in Column (1) of Table 1 but including only the mother's attitudes (regression not shown). The coefficient on mother's attitudes is about $50 \%$ larger than when father's attitudes are included in the regression. This provides an initial indication of the presence of positive assortative mating based on risk attitudes, an issue discussed in detail in Section 5. It also shows that it is important to include the attitudes of both parents in the regression specifications for Table 1 in order to be able to identify the distinct influences of mother's and father's attitudes.

In Column (2) of Table 1, we add exogenous controls— gender, age, and height—which were found previously to affect risk attitudes. This allows investigating whether parental and child attitudes are still related, once we control for similarity in personal characteristics. For example, tall parents tend to have tall children, which could potentially explain a similarity in risk attitudes. Alternatively, if personal characteristics do not explain the intergenerational correlation, this suggests a more direct relationship between attitudes of parents and their children, consistent with the transmission process assumed in models of attitude transmission. Not surprisingly, based on the results discussed in Section 2, the results indicate that daughters are less willing to take risks than sons and that taller and younger children are more likely to report that they are willing to take risks. Age and height of the parents do not have a statistically significant effect on children's willingness to take risks. More importantly, the positive relationship between children's and parents' willingness to take risks remains virtually the same as in Column (1) and is similarly significant after controlling for personal characteristics of parents and the child.

In Column (3), we add a variety of other controls for individual characteristics and environmental factors that could affect risk attitudes. These include characteristics of the region where the individual lived during the first 15 years of life (big city, city, small town, countryside, missing) and religion (catholic, protestant, other Christian, other religion, not a member of any church, missing information on religion), for the child and both parents, as well as indicators for child ethnicity (nationality on passport, aggregated into 17 categories). The regression also controls for subjective health status of parents and the child and an indicator for having lived in the German Democratic Rebublic (East Germany) before 1989. We also include fixed effects for children's and parents' current county-sized regions of residence. ${ }^{14}$ Finally, for the child and both parents we control for household income in 2004 and control for years of schooling as a proxy for permanent income. ${ }^{15}$ A caveat is that child income could be endogenous with respect to risk attitudes, so that interpreting coefficients on child income causally is inadvisable. Important for the question at hand, however, is the fact that the two coefficients of main interest,

14. Germany is divided geographically into 97 such regions, known as Raumordnungsregion, which are defined by the Federal Office for Building and Regional Planning and reflect an aggregation of administrative districts, something akin to counties in the U.S., taking into account economic agglomeration and commuting flows. Each region captures a centre of economic activity and its surrounding area and corresponds to a regional labour market.

15. In order to avoid dropping of observations due to missing observations, we set all missing observations to zero and include an indicator for missing schooling information. We also estimated all specifications with information on occupational prestige as a proxy for permanent income, instead of education. We use information on child and parental occupational prestige in the form of the Treiman standard international occupational prestige score, which takes discrete values from 13 to 78, where higher scores indicate higher prestige (see Ganzeboom and Treiman, 1996, for the methods used to construct the scale). As shown by Ermisch, Francesconi and Siedler (2006), this prestige measure exhibits a strong correlation with permanent income. This approach is useful mainly because it mitigates the problem of missing values on income and thus keeps the number of observations reasonably high. All results are qualitatively and quantitatively similar if we use occupational prestige instead of years of schooling as a proxy for permanent income. 
TABLE 2

Robustness to alternative risk measures

\begin{tabular}{|c|c|c|c|c|c|c|c|}
\hline \multirow[b]{3}{*}{ Dependent variable } & \multicolumn{6}{|c|}{ Child's willingness to take risks in the context of } & \multirow[b]{2}{*}{$\begin{array}{c}\text { Hypothetical } \\
\text { lottery } \\
\text { (amount) }\end{array}$} \\
\hline & General & $\begin{array}{c}\text { Car } \\
\text { driving }\end{array}$ & $\begin{array}{l}\text { Financial } \\
\text { matters }\end{array}$ & $\begin{array}{l}\text { Sports \& } \\
\text { leisure }\end{array}$ & Career & Health & \\
\hline & (1) & $(2)$ & (3) & (4) & (5) & (6) & (7) \\
\hline $\begin{array}{l}\text { Willingness to take risks: mother } \\
\text { (in respective context) }\end{array}$ & $\begin{array}{l}0 \cdot 149^{* * *} \\
{[0 \cdot 022]}\end{array}$ & $\begin{array}{l}0 \cdot 147^{* * *} \\
{[0 \cdot 023]}\end{array}$ & $\begin{array}{l}0 \cdot 136^{* * *} \\
{[0 \cdot 021]}\end{array}$ & $\begin{array}{l}0 \cdot 185^{* * *} \\
{[0 \cdot 021]}\end{array}$ & $\begin{array}{l}0 \cdot 177^{* * *} \\
{[0 \cdot 024]}\end{array}$ & $\begin{array}{l}0 \cdot 168^{* * *} \\
{[0 \cdot 022]}\end{array}$ & $\begin{array}{l}0 \cdot 177^{* * *} \\
{[0 \cdot 029]}\end{array}$ \\
\hline $\begin{array}{l}\text { Willingness to take risks: father } \\
\text { (in respective context) }\end{array}$ & $\begin{array}{l}0 \cdot 153^{* * *} \\
{[0 \cdot 023]}\end{array}$ & $\begin{array}{l}0 \cdot 143^{* * *} \\
{[0 \cdot 024]}\end{array}$ & $\begin{array}{l}0 \cdot 136^{* * *} \\
{[0 \cdot 022]}\end{array}$ & $\begin{array}{l}0 \cdot 163^{* * *} \\
{[0 \cdot 022]}\end{array}$ & $\begin{array}{l}0 \cdot 145^{* * *} \\
{[0 \cdot 025]}\end{array}$ & $\begin{array}{l}0 \cdot 135^{* * *} \\
{[0 \cdot 022]}\end{array}$ & $\begin{array}{l}0 \cdot 166^{* * *} \\
{[0 \cdot 026]}\end{array}$ \\
\hline Observations & 2985 & 2637 & 2892 & 2931 & 2547 & 2979 & 2975 \\
\hline $\mathrm{R}^{2}$ & $0 \cdot 21$ & $0 \cdot 23$ & $0 \cdot 21$ & $0 \cdot 25$ & $0 \cdot 23$ & $0 \cdot 19$ & $0 \cdot 10$ \\
\hline
\end{tabular}

Notes: The dependent variable in Columns (1)-(6) measures willingness to take risk in the particular context on a 11-point scale from 0 (completely unwilling to take risks) to 10 (completely willing to take risks), all of which are standardized. The dependent variable in Column (7) is the amount invested in the hypothetical lottery, answers are in categories of 0,20,000,40,000,60,000, 80,000, and 100,000 Euros, the measure is standardized. Explanatory risk variables in Columns (1)-(6) are coded on the 11-point scale from 0 (completely unwilling to take risks) to 10 (completely willing to take risks) and are all standardized. Explanatory variables in Column (7) are in Euro categories and standardized. The set of explanatory variables in Columns (1)-(7) is identical to that in Column (3) of Table 1. Coefficients are OLS estimates. Robust standard errors in brackets allow for clustering at the household level; ***, **, and * indicate significance at $1 \%, 5 \%$, and $10 \%$ level, respectively.

mother's and father's willingness to take risks, remain essentially unchanged relative to previous columns when we add income and the full array of other controls. Thus, there is a strong and significant relationship between children's and parents' risk attitudes, controlling for similarity across generations in a wide range of personal and environmental factors.

Table 2 explores whether the intergenerational correlation in risk attitudes is robust to using alternative survey measures. Each column uses a different question to measure risk attitudes for parents and children. The set of controls is the same as those in our full specification, Column (3) of Table 1. To facilitate comparison, in Column (1) we once again report the coefficients for the general risk question. Columns (2)-(6) report coefficient estimates using each of the five contextspecific questions, which ask about willingness to take risks in car driving, financial matters, sports and leisure, health, and career, respectively. As is evident from Table 2, the correlation of risk attitudes is significant at the $1 \%$ level for every context, for both mothers and fathers. Thus, the correlation in risk attitudes is not confined to the general risk question but is also observed for questions incorporating more specific contexts. One possibility is that the correlation is observed for all the different measures because they each measure the same underlying disposition towards risk. Another possibility is that the different measures capture distinct aspects of risk attitude that vary across contexts and that there is a distinct intergenerational correlation for each of these more specific characteristics. In Section 3.3, as part of additional robustness checks, we investigate the specificity of the intergenerational correlation in more detail.

Column (7) of Table 2 reports results based on a hypothetical lottery question. ${ }^{16}$ The measure differs from the others in that it uses a cardinal scale with seven response values: investment amounts of $0,20,000,40,000,60,000,80,000$, and 100,000. This question incorporates a different type of context and also includes given stakes and probabilities. The dependent variable is

16. The question asked individuals about how much of an endowment of 100,000 Euro they would invest in a lottery that would double or half their investment with probability 0.5 . 
the total amount invested by the child in the lottery, and parents' attitudes are indicated by their respective investment choices. There is substantial censoring at zero, due to the many individuals who choose to invest nothing in the lottery. Thus, in this case we report coefficients that are marginal effects, estimated using interval regression techniques that correct for censoring. The resulting intergenerational correlations are highly significant and positive. ${ }^{17}$ The results from the lottery measure provide a further indication that the intergenerational correlation is robust and show that it does not simply reflect a similar way of answering the type of qualitative, 11point response scales used for the other measures. The marginal effects shown in Column (7) of Table 2 imply that a parent increasing their investment by 1000 Euros causes a child to invest roughly an additional 250 Euros, which is substantial. ${ }^{18}$

An important final point regarding risk attitudes is that we have assumed so far that willingness to take risks and willingness to trust are distinct attitudes. One may argue, however, that trusting someone is a risky decision and thus that willingness to trust could partly reflect risk preference. On the other hand, there is no conceptual reason why risk preferences should be related to the belief-related component of willingness to trust, in the form of a prior about trustworthiness of others. It is important to know whether the trust measures capture something distinct from the measures of risk preference because only if this is the case we can sensibly talk about an independent correlation for risk and trust. To study this question, we ran the regressions reported in Column (4) of Table 1 where we regress children's willingness to take risks on parents' willingness to take risks and willingness to trust. We also control for the trust attitudes of children and include our standard controls as in Column (3). The marginal coefficients on mothers' and fathers' willingness to take risks are positive and significant and similar in size to those in Column (3). This shows that the disposition towards trust does not explain risk attitudes. This implies that trust attitudes do not simply measure attitudes towards risk and that the intergenerational correlations in risk and trust attitudes represent two distinct forms of attitude transmission.

In summary, the results show that the risk attitudes of parents are reflected in the willingness to take risks of the child and thus provide evidence for a process of intergenerational attitude transmission. In addition to being statistically significant, and robust to adding a large set of controls, the strength of attitude transmission across generations is substantial in magnitude if one compares to the types of intergenerational correlations typically studied by economists. For example, recent estimates put the intergenerational correlations in income and educational attainment in Germany at about 0.34 and 0.50, respectively (Solon, 2002; Heineck and Riphahn, 2009 ), and available estimates of the correlation in wealth (for the U.S.) range from 0.30 to 0.43 (Mulligan, 1997; Charles and Hurst, 2003). Our estimates indicate that increasing both parents' risk attitudes by one S.D. increases the child's willingness to take risks by $0 \cdot 32$, which is of the same order of magnitude as the intergenerational correlation in wealth.

\subsection{Trust attitudes}

We now turn to the analysis of the intergenerational correlation in trust. Since we are interested in behaviourally valid measures, we collapse agreement with the three statements into a single

17. We also estimated a Probit model, available upon request, where the dependent variable is equal to 1 if the child invested a positive amount and 0 otherwise. Regressors included indicators for positive investment by mother and father and the same controls as in Column (7). In this case, the probability that a child invests increases by $0 \cdot 16$ if the father invests and $0 \cdot 11$ if the mother invests. Parental investment is highly statistically significant and quantitatively more important than any other control in the regression.

18. One Euro was worth approximately $1 \cdot 2$ U.S. dollars on average during the period when interviews were conducted. 
component, as was done in the validation study by Fehr et al. (2003). ${ }^{19}$ In Section 3.3, however, we also assess the robustness of the results to analysing agreement with each statement separately.

Figure 2 plots children's average values of the trust measure, constructed via principal component analysis, for given values of the same trust measure of mothers (lower left diagram) and fathers (lower right diagram). The regression lines are weighted by the number of observations of children whose parents' trust measure takes a particular value. The upward slopes of the weighted regression lines give an initial indication that children's tendency to trust is increasing in their parents' willingness to trust.

To test the relationship suggested in Figure 2 more rigourously, we ran three regressions for trust attitudes analogous to the ones reported for risk. The results are displayed in Columns (4)(8) of Table 1. The dependent variable is the (standardized) principal component ("trust") of the child, which is regressed on the respective standardized principal components of the mother and father, respectively. In Column (5), no further controls are added. The coefficients for parents' trust attitudes are positive and significant at any conventional level, indicating the presence of a positive intergenerational correlation. As was the case for risk, child attitudes are related to attitudes of both the mother and the father. An interesting difference, however, is that the coefficient for mother is significantly larger than the coefficient for father in the case of trust attitudes ( $p$-value $<0.02$ ), whereas there was no significant difference for risk attitudes ( $p$-value $<0.79$ ). As for risk attitudes, the coefficient on mother's attitudes is even larger if father's attitudes are excluded from the regression, in this case by about $30 \%$ (regression not shown). The coefficients remain basically unchanged and highly significant when we add further controls in Columns (6) and (7). The intergenerational transmission of trust attitudes is also substantial in magnitude: changing the attitudes of both parents by one S.D. increases the child's trust by 0.40 .

Concerning the relation between trust and risk, in Column (8) we regress children's trust jointly on parents' willingness to take risks and their trust attitudes, together with the controls as in Column (7). We find that the coefficients on mothers' and fathers' trust are positive and highly significant and similar to those obtained in the specifications without controlling for risk attitudes. $^{20}$

\subsection{Robustness}

3.3.1. Collaboration on survey responses. A potential concern regarding the results shown in Table 1 is that correlations could be driven by parents and children somehow coordinating on how to answer different questions. While this is potentially a very serious concern, we are confident that it does not explain the findings. First, interviewers are specifically instructed to administer the survey individually and to make sure that different household members answer independently. If for some reason one household member wants to fill in the paper survey at the same time that the interviewer conducts a personal interview with another household member, the interviewer is instructed to ensure that these two survey respondents are in different rooms. Therefore, collaboration is ruled out by design. Second, filling out a survey involves answering about 150 question modules. Thus, even if respondents did have some limited communication during the interview, despite the best efforts of the interviewer, it is very unlikely that this applies systematically to the small subset of questions that are the key variables in this study. Third, we have estimated all the regressions in Table 1, excluding from the sample observations of

19. We collapse the measures using principal component analysis, as described in footnote 10 .

20. We find similar results if we instead use the hypothetical lottery question, or other risk questions, as the measure of risk preference in the regression. 
parents-child pairs if one of the three individuals had sent in the questionnaire answers by surface mail, i.e. answered the survey without the interviewer being present. In this case, we find a similar and significant intergenerational correlation in risk and trust attitudes. Fourth, we also estimated the same regressions using about $40 \%$ of children in the sample who live in a separate household from their parents. In this case, the intergenerational correlation is still highly significant for both mothers and fathers, for both risk and trust (the correlations for trust are essentially unchanged; for risk the correlations are somewhat smaller but the combined effect of both parents is still large). Fifth, the correlations obtained from using just the sample of children living with their parents yield similar results to using the whole sample. Finally, we have also restricted the sample to parents-child pairs who all participated in CAPI interviews only; this excludes the possibility that questionnaires were completed simultaneously because only one person at a time can possibly fill out the survey on the laptop. Again, we find significant correlations similar to those in Table 1. These findings make us confident that the results are not driven by collaboration between family members.

3.3.2. Scale use. The fact that we observe a strong correlation in economic attitudes, across various survey measures with different scales, suggests that the results are not explained simply by patterns of scale use being shared by parents and children. As an additional robustness check, however, we investigated the intergenerational correlation in risk attitudes excluding families who exhibit a particularly salient heuristic for scale use, namely choosing the midpoint of the scale. We actually find a stronger intergenerational correlation in risk attitudes after eliminating child-parents pairs where the child and both parents make identical choices by choosing 5 on the scale. This indicates that the results are not driven by a similar tendency within families to choose the midpoint of response scales.

Another indication that scale use does not drive the intergenerational correlation comes from a detailed analysis of the context-specific measures of risk attitudes and the individual trust measures. For example, parents differ in reported willingness to take risks across contexts. If these same differences are observed in the child, this is difficult to explain with scale use, given that all the context-specific measures involve exactly the same 11-point scale. In Columns (1)(6) of Table 3, we regress children's answers to a given risk question on parents' responses to all the risk questions simultaneously. We also control for children's answers to all contextspecific risk questions. Table 3 reveals that the respective estimated coefficients, which are found along the diagonal of the table, are all positive and highly significant. Thus, controlling for risk attitudes in all other contexts, children's in a given context are strongly and significantly associated with those of their parents in that same context. Moreover, most other coefficients off the diagonal are not significant; if they are significant, they are typically smaller than those on the diagonal. Thus, parents' attitudes in a given context are the best predictor of a child's attitudes in that same context. ${ }^{21}$ These results shed further doubt on the scale-use hypothesis and are also interesting in their own right. It is noteworthy that children are not just similar to their parents in terms of a general disposition towards risk-taking but are similar in an even more precise sense. Thus, attitude transmission appears to be a fine-tuned process, and children end up like the parents even in a very detailed sense.

In Table 4, we perform the same exercise as in Table 1 but use answers to three trust questions separately instead of the principal component. As with risk attitudes, within-parent differences in responses to the different contexts are observed in the child, holding the response scale constant.

21. Note that context-specific measures tend to be correlated for an individual (ranging from $0 \cdot 26$ to $0 \cdot 45$ ), making the diagonal result all the more striking. 
TABLE 3

Specificity of the intergenerational correlation in risk attitudes

\begin{tabular}{|c|c|c|c|c|c|c|}
\hline \multirow[b]{3}{*}{ Dependent variable } & \multicolumn{6}{|c|}{ Child's willingness to take risks in the context of } \\
\hline & General & $\begin{array}{c}\text { Car } \\
\text { driving }\end{array}$ & $\begin{array}{c}\text { Financial } \\
\text { matters }\end{array}$ & $\begin{array}{l}\text { Sports \& } \\
\text { leisure }\end{array}$ & Career & Health \\
\hline & (1) & (2) & (3) & (4) & (5) & (6) \\
\hline \multicolumn{7}{|c|}{$\begin{array}{l}\text { Willingness to take risks } \\
\text { in the context of }\end{array}$} \\
\hline \multirow{2}{*}{ General: mother } & & & & & & \\
\hline & $\begin{array}{l}0.084 \\
{[0 \cdot 025]}\end{array}$ & $\begin{array}{l}-0.022 \\
{[0.025]}\end{array}$ & $\begin{array}{l}-0.015 \\
{[0 \cdot 026]}\end{array}$ & $\begin{array}{c}0.020 \\
{[0 \cdot 023]}\end{array}$ & $\begin{array}{c}0.027 \\
{[0 \cdot 024]}\end{array}$ & $\begin{array}{l}-0 \cdot 041 \\
{[0 \cdot 025]}\end{array}$ \\
\hline \multirow[t]{2}{*}{ General: father } & $0.086^{* * *}$ & -0.027 & $-0.054^{*}$ & -0.015 & $0 \cdot 018$ & -0.014 \\
\hline & {$[0 \cdot 025]$} & {$[0 \cdot 027]$} & [0.029] & {$[0 \cdot 025]$} & {$[0 \cdot 026]$} & [0.028] \\
\hline \multirow[t]{2}{*}{ Driving: mother } & $-0.046^{* *}$ & $0 \cdot 114^{* * *}$ & 0.012 & -0.007 & -0.016 & $-0 \cdot 015$ \\
\hline & {$[0 \cdot 023]$} & {$[0 \cdot 026]$} & {$[0 \cdot 025]$} & {$[0 \cdot 022]$} & [0.024] & {$[0 \cdot 025]$} \\
\hline \multirow[t]{2}{*}{ Driving: father } & 0.005 & $0.097^{* * *}$ & -0.020 & 0.009 & -0.006 & -0.022 \\
\hline & {$[0 \cdot 024]$} & {$[0 \cdot 026]$} & {$[0 \cdot 026]$} & {$[0 \cdot 023]$} & {$[0 \cdot 025]$} & {$[0 \cdot 025]$} \\
\hline \multirow[t]{2}{*}{ Financial: mother } & 0.019 & $-0 \cdot 045^{*}$ & $0 \cdot 114^{* * *}$ & -0.016 & $-0.041^{*}$ & -0.006 \\
\hline & [0.023] & {$[0 \cdot 026]$} & {$[0 \cdot 027]$} & {$[0 \cdot 022]$} & {$[0 \cdot 025]$} & {$[0 \cdot 026]$} \\
\hline \multirow[t]{2}{*}{ Financial: father } & -0.025 & 0.024 & $0 \cdot 089^{* * *}$ & 0.036 & -0.028 & -0.036 \\
\hline & [0.024] & {$[0 \cdot 027]$} & {$[0 \cdot 025]$} & {$[0 \cdot 024]$} & {$[0 \cdot 026]$} & {$[0 \cdot 026]$} \\
\hline \multirow[t]{2}{*}{ Sports: mother } & -0.020 & 0.005 & $-0.058^{* *}$ & $0 \cdot 111^{* * *}$ & -0.030 & 0.012 \\
\hline & {$[0 \cdot 025]$} & {$[0 \cdot 030]$} & {$[0 \cdot 028]$} & {$[0 \cdot 025]$} & [0.027] & {$[0 \cdot 027]$} \\
\hline \multirow[t]{2}{*}{ Sports: father } & -0.022 & -0.038 & 0.032 & $0.090^{* * *}$ & 0.019 & -0.022 \\
\hline & {$[0 \cdot 026]$} & {$[0 \cdot 027]$} & {$[0 \cdot 026]$} & {$[0 \cdot 025]$} & {$[0 \cdot 026]$} & [0.027] \\
\hline \multirow[t]{2}{*}{ Career: mother } & 0.004 & $-0 \cdot 001$ & -0.016 & 0.019 & $0 \cdot 080^{* * *}$ & $-0 \cdot 021$ \\
\hline & {$[0 \cdot 026]$} & {$[0 \cdot 030]$} & {$[0 \cdot 030]$} & {$[0 \cdot 026]$} & {$[0 \cdot 028]$} & [0.029] \\
\hline \multirow[t]{2}{*}{ Career: father } & -0.022 & 0.001 & $0.051^{*}$ & -0.030 & $0 \cdot 084^{* * *}$ & $-0 \cdot 014$ \\
\hline & {$[0 \cdot 026]$} & [0.027] & {$[0 \cdot 028]$} & {$[0 \cdot 026]$} & {$[0 \cdot 028]$} & {$[0 \cdot 029]$} \\
\hline \multirow[t]{2}{*}{ Health: mother } & 0.019 & -0.028 & -0.016 & $-0.045^{* *}$ & 0.015 & $0 \cdot 102^{* * *}$ \\
\hline & {$[0 \cdot 023]$} & {$[0 \cdot 026]$} & {$[0 \cdot 028]$} & {$[0 \cdot 022]$} & {$[0 \cdot 024]$} & {$[0 \cdot 026]$} \\
\hline \multirow[t]{2}{*}{ Health: father } & -0.035 & -0.008 & -0.037 & $-0.037^{*}$ & $-0 \cdot 045 *$ & $0 \cdot 145^{* * *}$ \\
\hline & {$[0 \cdot 022]$} & {$[0 \cdot 024]$} & {$[0 \cdot 025]$} & {$[0 \cdot 021]$} & {$[0 \cdot 024]$} & {$[0 \cdot 025]$} \\
\hline Additional controls & Yes & Yes & Yes & Yes & Yes & Yes \\
\hline Observations & 2311 & 2311 & 2311 & 2311 & 2311 & 2311 \\
\hline $\mathrm{R}^{2}$ & 0.536 & 0.489 & 0.443 & 0.572 & 0.529 & 0.472 \\
\hline
\end{tabular}

Notes: The dependent variable in each column measures willingness to take risk in the particular context on a 11point scale from 0 (completely unwilling to take risks) to 10 (completely willing to take risks) and is standardized. Explanatory risk variables are coded on the 11-point scale and standardized as well. Coefficients in all columns are OLS estimates. Robust standard errors in brackets allow for correlation of errors at the household level; ***, **, and $*$ indicate significance at $1 \%, 5 \%$, and $10 \%$ level, respectively. Additional controls include years of schooling of child and child's father and mother; corresponding indicator variables for missing schooling information; indicator variables for characteristics of the residence of youth before the age of 16, for child and parents (big city, city, countryside, missing; the reference category is small town); indicator variables for religion of child and parents (catholic, protestant, other non-Christian, no religious affiliation, missing religion; the reference category is other Christian), gross annual household income for child, child's mother and father, subjective health status of child, and child's mother and father (five response categories), and fixed effects for region (Raumordnungsregion) and 17 nationality-ethnicity dummies (reference category is German). All religion information is obtained from the 2003 wave of the SOEP. A substantial fraction, roughly fourth, of the sample do not have complete answers to risk questions in all contexts due to item nonresponse, in particular when the question does not apply (e.g. car driving for 17-year-old individuals). 
TABLE 4

Specificity of the intergenerational correlation in trust

\begin{tabular}{|c|c|c|c|}
\hline & General trust & Reliability & Need for caution \\
\hline Dependent variable is child's & (1) & (2) & (3) \\
\hline \multirow{2}{*}{ Trust: mother } & $0 \cdot 156^{* * *}$ & $0 \cdot 053^{* *}$ & $-0 \cdot 016$ \\
\hline & {$[0 \cdot 025]$} & {$[0 \cdot 024]$} & {$[0 \cdot 023]$} \\
\hline \multirow[t]{2}{*}{ Trust: father } & $0 \cdot 098^{* * *}$ & $0 \cdot 040^{*}$ & $0 \cdot 042^{*}$ \\
\hline & {$[0 \cdot 025]$} & {$[0 \cdot 024]$} & {$[0 \cdot 025]$} \\
\hline \multirow[t]{2}{*}{ Reliability: mother } & 0.034 & $0 \cdot 124^{* * *}$ & 0.028 \\
\hline & {$[0 \cdot 023]$} & {$[0 \cdot 024]$} & {$[0 \cdot 024]$} \\
\hline \multirow[t]{2}{*}{ Reliability: father } & 0.035 & $0 \cdot 147^{* * *}$ & $0 \cdot 013$ \\
\hline & {$[0 \cdot 025]$} & {$[0 \cdot 026]$} & {$[0 \cdot 025]$} \\
\hline \multirow[t]{2}{*}{ Caution: mother } & $0 \cdot 043^{* *}$ & -0.014 & $0 \cdot 152^{* * *}$ \\
\hline & {$[0 \cdot 021]$} & {$[0 \cdot 022]$} & {$[0 \cdot 023]$} \\
\hline \multirow[t]{2}{*}{ Caution: father } & $0 \cdot 017$ & -0.010 & $0 \cdot 081^{* * *}$ \\
\hline & {$[0 \cdot 021]$} & {$[0 \cdot 022]$} & {$[0 \cdot 022]$} \\
\hline \multirow[t]{2}{*}{ Trust: child } & & $-0.422^{* * *}$ & $-0 \cdot 134^{* * *}$ \\
\hline & & {$[0 \cdot 022]$} & {$[0 \cdot 023]$} \\
\hline \multirow[t]{2}{*}{ Reliability: child } & $-0.431^{* * *}$ & & $0 \cdot 185^{* * *}$ \\
\hline & {$[0 \cdot 022]$} & & {$[0 \cdot 023]$} \\
\hline \multirow[t]{2}{*}{ Caution: child } & $-0 \cdot 118^{* * *}$ & $0 \cdot 159^{* * *}$ & \\
\hline & {$[0 \cdot 021]$} & {$[0 \cdot 019]$} & \\
\hline \multirow[t]{2}{*}{1 if female } & 0.036 & 0.009 & -0.016 \\
\hline & {$[0 \cdot 054]$} & {$[0 \cdot 053]$} & {$[0 \cdot 054]$} \\
\hline \multirow[t]{2}{*}{ Age of child (years) } & $0 \cdot 006$ & -0.007 & $0 \cdot 006$ \\
\hline & {$[0 \cdot 005]$} & {$[0 \cdot 005]$} & {$[0 \cdot 005]$} \\
\hline \multirow[t]{2}{*}{ Height of child (cm) } & -0.000 & -0.003 & 0.005 \\
\hline & {$[0 \cdot 003]$} & {$[0 \cdot 003]$} & {$[0 \cdot 003]$} \\
\hline \multirow[t]{2}{*}{ Age of mother (years) } & $0 \cdot 004$ & $0 \cdot 014^{* *}$ & $0 \cdot 001$ \\
\hline & {$[0 \cdot 006]$} & {$[0 \cdot 006]$} & {$[0 \cdot 006]$} \\
\hline \multirow[t]{2}{*}{ Age of father (years) } & -0.005 & -0.007 & 0.004 \\
\hline & {$[0 \cdot 005]$} & {$[0 \cdot 005]$} & {$[0 \cdot 005]$} \\
\hline \multirow[t]{2}{*}{ Height of mother $(\mathrm{cm})$} & $0.006^{*}$ & 0.002 & 0.001 \\
\hline & {$[0 \cdot 003]$} & {$[0.003]$} & {$[0 \cdot 003]$} \\
\hline \multirow[t]{2}{*}{ Height of father $(\mathrm{cm})$} & -0.002 & 0.002 & $-0 \cdot 003$ \\
\hline & {$[0 \cdot 003]$} & {$[0 \cdot 003]$} & {$[0.003]$} \\
\hline \multirow[t]{2}{*}{ Constant } & $-1 \cdot 704^{* *}$ & -0.676 & -0.934 \\
\hline & {$[0.743]$} & {$[0.732]$} & [0.769] \\
\hline Additional controls & Yes & Yes & Yes \\
\hline Observations & 2601 & 2601 & 2601 \\
\hline $\mathrm{R}^{2}$ & $0 \cdot 390$ & 0.405 & 0.293 \\
\hline
\end{tabular}

Notes: The measures for general trust, reliability, and need for caution reflect agreement or disagreement with corresponding statements on a four-point scale. The statements are "In general, one can trust people.", "In these days you cannot rely on anybody else.", and "When dealing with strangers it is better to be cautious when dealing with them.", respectively. Answers are reported on a four-category scale from "strongly agree" to "strongly disagree". All dependent and explanatory variables are standardized. Coefficients in all columns are OLS estimates. Robust standard errors in brackets allow for clustering at the household level; ***, **, and * indicate significance at $1 \%, 5 \%$, and $10 \%$ level, respectively. Additional controls include years of schooling of child and child's father and mother; corresponding indicator variables for missing schooling information; indicator variables for characteristics of the residence of youth before the age of 16 , for child and parents (big city, city, countryside, missing; the reference category is small town); indicator variables for religion of child and parents (catholic, protestant, other non-Christian, no religious affiliation, missing religion; the reference category is other Christian), gross annual household income for child, child's mother and father, subjective health status of child, and child's mother and father (five response categories), and fixed effects for region (Raumordnungsregion) and 17 nationality-ethnicity dummies (reference category is German). All religion information is obtained from the 2003 wave of the SOEP. 
3.3.3. Reverse causality. Some of the findings already suggest that the intergenerational correlation in attitudes is unlikely to be explained by reverse causality from the child to the parents. For example, parental attitudes in contexts such as career strongly predict child attitudes in the same context, even controlling for attitudes in other contexts. Given that parental career is often largely determined by the time a child is born, due to a whole sequence of educational and other choices, the intergenerational correlation in this context is unlikely to be driven by reverse causality. We also show in Section 4 that child attitudes are related to the prevailing attitude in the region. It is clearly not plausible that child attitudes influence the average attitude in the region, whereas socialization of the child by parents and other role models can explain both results. One common way to investigate the issue of causality further, however, is to use an instrumental variable approach, which is what we pursue in this section.

Previous research has used cultural characteristics, such as religion, as instruments for attitudes such as trust. Historically, different religions have been associated with different economically relevant attitudes, most famously Protestantism and attitudes towards work as discussed by Weber (1930). More recently, Guiso, Sapienza and Zingales (2003) use the World Values Survey and find significant differences in trust by religion. McCleary and Barro (2006) pursue a similar approach, although they find less evidence that religious belief (belief in hell) is related to trust. In our investigation of exogenous traits that are related to attitudes, described at the end of Section 2, we found that religion affects risk attitudes of children. Performing these same types of regressions for mothers and fathers separately, we also find a similar impact of religion, although the effect is stronger for mothers. ${ }^{22}$ As is the case for children, religion has little impact on mothers' and fathers' trust, indicating that religion may work less well as an instrument for trust in our data. Other parental characteristics are also related to parental risk and trust attitudes, including years of education and characteristics of the region of residence during youth. These are potential instruments by virtue of being plausibly exogenous with respect to child attitudes, i.e. the assumption that these satisfy the exclusion restriction appears to be valid.

In Table 5, we instrument for parents' attitudes and control for child religion, region of youth, and years of education to rule out that the instruments affect child attitudes solely through a correlation with these child characteristics. In Columns (1)-(3), we find a strong positive impact of mother's and father's (instrumented) risk attitudes on the child's attitudes, respectively, except in Column (3) where father's attitude is no longer significant. The latter result could indicate that for fathers previous results were biased upwards, but it seems more likely that the IV estimates for fathers suffer more from problems of weak instruments. Indeed, in the first stage for Column (3), the $F$-test for mothers is around 6, whereas for fathers it is only about 4. ${ }^{23}$ In Columns (4)-(6) of Table 5, coefficients for mothers' and fathers' instrumented trust attitudes are positive and large, but only mother's trust is significant. Again, first-stage $F$-tests are relatively low, particularly in Column (6). Overall, the results reinforce the case against reverse causality as the main explanation for the intergenerational correlations, but given that the instruments are not particularly strong, we take the IV estimates as additional suggestive evidence.

3.3.4. Risk and trust attitudes versus personality. Psychologists have frequently documented intergenerational correlations in personality type. ${ }^{24} \mathrm{~A}$ natural question is whether risk

22. Results available upon request.

23. We find qualitatively similar results instrumenting using only parental religion.

24. For example, Loehlin, Horn and Willerman (1981) report median correlations on the order of $0 \cdot 10$ for various personality dimensions and about $0 \cdot 20$ for various attitudes. 
TABLE 5

The relationship between children's and parents' attitudes: IV results

\begin{tabular}{|c|c|c|c|c|c|c|}
\hline \multirow[b]{2}{*}{ Dependent variable } & \multicolumn{3}{|c|}{$\begin{array}{l}\text { Child's willingness to } \\
\text { take risks in general }\end{array}$} & \multicolumn{3}{|c|}{$\begin{array}{c}\text { Child's trust } \\
\text { (principal component) }\end{array}$} \\
\hline & (1) & (2) & (3) & (4) & (5) & (6) \\
\hline $\begin{array}{l}\text { Mother's willingness to } \\
\text { take risks in general }\end{array}$ & $\begin{array}{l}0 \cdot 255^{* * *} \\
{[0 \cdot 086]}\end{array}$ & & $\begin{array}{l}0 \cdot 229^{* *} \\
{[0 \cdot 100]}\end{array}$ & & & \\
\hline $\begin{array}{l}\text { Father's willingness to } \\
\text { take risks in general }\end{array}$ & & $\begin{array}{c}0 \cdot 190^{*} \\
{[0 \cdot 099]}\end{array}$ & $\begin{array}{c}0.026 \\
{[0 \cdot 116]}\end{array}$ & & & \\
\hline Trust: mother & & & & $\begin{array}{l}0 \cdot 842^{* * *} \\
{[0 \cdot 126]}\end{array}$ & & $\begin{array}{l}0 \cdot 371^{* *} \\
{[0 \cdot 163]}\end{array}$ \\
\hline Trust: father & & & & & $\begin{array}{l}0 \cdot 585^{* * *} \\
{[0 \cdot 085]}\end{array}$ & $\begin{array}{r}0.259^{*} \\
{[0 \cdot 151]}\end{array}$ \\
\hline 1 if female & $\begin{array}{c}-0.231^{* * *} \\
{[0 \cdot 047]}\end{array}$ & $\begin{array}{c}-0 \cdot 233^{* * *} \\
{[0 \cdot 049]}\end{array}$ & $\begin{array}{c}-0 \cdot 232^{* * *} \\
{[0 \cdot 048]}\end{array}$ & $\begin{array}{r}-0 \cdot 012 \\
{[0 \cdot 056]}\end{array}$ & $\begin{array}{l}-0.008 \\
{[0.052]}\end{array}$ & $\begin{array}{l}-0 \cdot 008 \\
{[0 \cdot 049]}\end{array}$ \\
\hline Age of child (years) & $\begin{array}{l}-0 \cdot 016^{* * *} \\
{[0 \cdot 004]}\end{array}$ & $\begin{array}{c}-0 \cdot 017^{* * *} \\
{[0 \cdot 004]}\end{array}$ & $\begin{array}{l}-0 \cdot 016^{* * *} \\
{[0 \cdot 004]}\end{array}$ & $\begin{array}{c}0 \cdot 001 \\
{[0 \cdot 004]}\end{array}$ & $\begin{array}{l}-0 \cdot 004 \\
{[0 \cdot 003]}\end{array}$ & $\begin{array}{l}-0 \cdot 003 \\
{[0 \cdot 003]}\end{array}$ \\
\hline Height of child $(\mathrm{cm})$ & $\begin{array}{l}0 \cdot 009^{* * *} \\
{[0 \cdot 003]}\end{array}$ & $\begin{array}{l}0 \cdot 009^{* * *} \\
{[0 \cdot 003]}\end{array}$ & $\begin{array}{l}0 \cdot 009^{* * *} \\
{[0 \cdot 003]}\end{array}$ & $\begin{array}{c}0 \cdot 001 \\
{[0 \cdot 003]}\end{array}$ & $\begin{array}{c}0 \cdot 003 \\
{[0 \cdot 003]}\end{array}$ & $\begin{array}{c}0 \cdot 003 \\
{[0 \cdot 003]}\end{array}$ \\
\hline Constant & $\begin{array}{c}-1 \cdot 139^{* *} \\
{[0 \cdot 513]}\end{array}$ & $\begin{array}{c}-1 \cdot 226^{* *} \\
{[0 \cdot 524]}\end{array}$ & $\begin{array}{c}-1 \cdot 139^{* *} \\
{[0 \cdot 517]}\end{array}$ & $\begin{array}{l}-0.153 \\
{[0.573]}\end{array}$ & $\begin{array}{l}-0.446 \\
{[0.536]}\end{array}$ & $\begin{array}{l}-0 \cdot 386 \\
{[0 \cdot 503]}\end{array}$ \\
\hline \multicolumn{7}{|l|}{ Additional controls } \\
\hline Observations & 3333 & 3333 & 3333 & 3253 & 3250 & 3250 \\
\hline$R^{2}$ second stage (centred) & 0.09 & 0.09 & $0 \cdot 10$ & $-0 \cdot 16$ & $-0 \cdot 01$ & $0 \cdot 09$ \\
\hline First-stage partial $R^{2}$ (mother) & 0.04 & & 0.03 & 0.02 & & $0 \cdot 02$ \\
\hline First-stage F(2,50) (mother) & 9.99 & & $6 \cdot 19$ & $5 \cdot 24$ & & $5 \cdot 97$ \\
\hline First-stage partial $R^{2}$ (father) & & 0.03 & 0.03 & & 0.05 & 0.02 \\
\hline First-stage $F(2,50)$ (father) & & $7 \cdot 32$ & $4 \cdot 23$ & & $9 \cdot 20$ & $6 \cdot 99$ \\
\hline $\begin{array}{l}\text { Hansen overidentification } \\
\text { (p-value) }\end{array}$ & 0.22 & 0.78 & $0 \cdot 21$ & 0.67 & 0.52 & $0 \cdot 34$ \\
\hline
\end{tabular}

Notes: The dependent variable in Columns (1)-(3) measures general willingness to take risk on a 11-point scale from 0 (completely unwilling to take risks) to 10 (completely willing to take risks) and is standardized. Parental risk variables are measured on the 11-point scale and standardized as well. The dependent variable in Columns (4)-(6) measures trust as the principal component obtained from agreement with three statements regarding trust (general trust, reliance on others, need for caution in dealing with strangers) measured on a four-point scale. The measures are standardized. Parental trust variables are obtained by a similar procedure and are standardized as well. Coefficients in all columns are second-stage IV estimates. Instruments for parental risk variables in Columns (1)-(3) and for parental trust variables in Columns (4)-(6) are parental religion variables (catholic, protestant, other non-Christian, no religion, missing religion; the reference category is other Christian), exogenous parental characteristics (age, height), parental education (years of schooling of mother and father, respectively; corresponding indicator variables for missing schooling information), and indicator variables for characteristics of the residence of youth of mother and father, respectively, before the age of 16 (big city, city, countryside, missing; the reference category is small town). Additional controls include child's education, religion, and residence of youth. All religion information is obtained from the 2003 wave of the SOEP.

and trust attitudes are proxies for the personality constructs studied in psychology in which case transmission of risk and trust attitudes is a reflection of the intergenerational transmission of personality. Previous evidence, however, suggests that this is not the case: economic attitudes such as risk preference are distinct from personality measures (Borghans et al., 2008; Borghans, Meijers and Ter Weel, 2008; Dohmen et al., 2008). Furthermore, we have measures of the "Big Five" personality traits for individuals, which allows us to empirically disentangle transmission of personality from transmission of risk and trust attitudes. We investigate this question by estimating the same regressions as in Table 1 but adding the personality traits of the child and 
both parents as controls. We find intergenerational correlations in personality traits within the range typically found in the psychology literature. More importantly, the coefficients for risk and trust attitudes are essentially unchanged compared to when personality traits are omitted. ${ }^{25}$ This shows that transmission of risk and trust attitudes is a distinct process from transmission of personality studied by psychologists.

\section{THE IMPACT OF REGIONAL RISK AND TRUST ATTITUDES}

So far we have shown that parental attitudes have a substantial impact on child attitudes. This does not rule out, however, that other individuals in the environment influence the child as well. Theories of attitude formation typically assume that child attitudes may be affected by other local role models, in addition to parents. Table 6 investigates whether prevailing attitudes in a child's region of residence have explanatory power for child attitudes. The table reports results using the specification from Columns (2) and (6) of Table 1 but adding controls for average attitudes in the region. The average is calculated using all participants in the SOEP data set with nonmissing attitudes in order to obtain the best estimate. The sample used to calculate the average is substantially larger than the one used for the regression analysis because it includes individuals for whom we do not observe parents. We exclude the child's attitude when calculating the regional average. Columns (1) and (3) report the results from Table 1, for ease of comparison, and Columns (2) and (4) show results for risk and trust, respectively, once we control for regional attitudes. The coefficients for regional attitudes are positive and highly significant in Columns (2) and (4), controlling for parental attitudes. This indicates that child attitudes are influenced by attitudes in the environment, controlling for parental attitudes.

To check whether the results in Table 6 could reflect sorting of children into regions with similar attitudes to their own, we estimated the same regressions using only the sample of children who currently live with their parents and thus presumably did not choose their region of residence. Parents might sort into regions based on attitudes, but we control for parental attitudes in the regression. In this case, we again find a positive and significant impact of regional attitudes on the child, for both risk and trust attitudes. ${ }^{26}$ We conclude that the evidence is consistent with prevailing attitudes in the local area influencing child attitudes.

An important final point is that a role for regional attitudes in influencing the child does not conflict with the previous conclusion that parents matter for child attitudes. Note that in Table 6 the coefficients on parental attitudes are essentially unchanged when we control for regional attitudes compared to Columns (1) and (3). This is consistent with our previous results showing that including regional fixed effects does not affect the relationship between parental and child attitudes. We also pursued another approach to investigating whether the correlation between parent and child attitudes could be spurious and driven by similarity in region characteristics. We randomly rematch parents and children with members of other families living in the same region and test whether the correlation in these synthetic families is similar to the correlation observed within real families. If this were the case, this would suggest that the driver of similar attitudes within families is the fact that they often share the same region of residence. Panels (a) and (b) of Figure 3 present histograms of the correlations of risk attitudes between child and mother and child and father, respectively, in 500 samples where parents are randomly

25. Results available upon request.

26. Results are similar eliminating the small number of children who are living with very old parents (parents age 70 and older) and alternatively when eliminating children who live with their parents and are relatively old themselves (children age 40 and older). In such situations, it could be the case that the child chose the region and parents moved in with the child due to old-age-related infirmity. 
TABLE 6

The role of regional attitudes

\begin{tabular}{|c|c|c|c|c|c|c|}
\hline \multirow[b]{2}{*}{ Dependent variable } & \multicolumn{3}{|c|}{$\begin{array}{l}\text { Child's willingness to } \\
\text { take risks in general }\end{array}$} & \multicolumn{3}{|c|}{$\begin{array}{l}\text { Child's trust } \\
\text { (principal component) }\end{array}$} \\
\hline & (1) & (2) & (3) & (4) & (5) & (6) \\
\hline \multirow{6}{*}{$\begin{array}{l}\text { Mother's willingness to } \\
\text { take risks in general } \\
\text { Father's willingness to } \\
\text { take risks in general } \\
\text { Average regional willingness } \\
\text { to take risks in general }\end{array}$} & $0 \cdot 154^{* * *}$ & $0 \cdot 140^{* * *}$ & $0 \cdot 141^{* * *}$ & & & \\
\hline & {$[0 \cdot 019]$} & {$[0 \cdot 019]$} & {$[0 \cdot 019]$} & & & \\
\hline & $0 \cdot 143^{* * *}$ & $0.135^{* * *}$ & $0 \cdot 134^{* * *}$ & & & \\
\hline & {$[0 \cdot 020]$} & {$[0 \cdot 020]$} & {$[0 \cdot 020]$} & & & \\
\hline & & $0 \cdot 363^{* * *}$ & $0.461^{* * *}$ & & & \\
\hline & & {$[0 \cdot 078]$} & {$[0 \cdot 082]$} & & & \\
\hline \multirow[t]{2}{*}{ Trust: mother } & & & & $0 \cdot 235^{* * *}$ & $0 \cdot 217^{* * *}$ & $0 \cdot 217^{* * *}$ \\
\hline & & & & {$[0 \cdot 020]$} & {$[0 \cdot 020]$} & {$[0 \cdot 020]$} \\
\hline \multirow[t]{2}{*}{ Trust: father } & & & & $0 \cdot 157^{* * *}$ & $0 \cdot 142^{* * *}$ & $0 \cdot 143^{* * *}$ \\
\hline & & & & {$[0 \cdot 020]$} & {$[0 \cdot 020]$} & {$[0 \cdot 020]$} \\
\hline \multirow{2}{*}{$\begin{array}{l}\text { Average regional trust } \\
\text { (principal component) }\end{array}$} & & & & & $0.476^{* * *}$ & $0.441^{* * *}$ \\
\hline & & & & & {$[0 \cdot 074]$} & {$[0 \cdot 076]$} \\
\hline \multirow[t]{2}{*}{1 if female } & $-0 \cdot 229^{* * *}$ & $-0.227^{* * *}$ & $-0 \cdot 240^{* * *}$ & 0.000 & 0.003 & -0.006 \\
\hline & {$[0 \cdot 051]$} & {$[0 \cdot 051]$} & {$[0 \cdot 051]$} & {$[0 \cdot 052]$} & {$[0 \cdot 051]$} & {$[0 \cdot 051]$} \\
\hline \multirow[t]{2}{*}{ Age of child (years) } & $-0 \cdot 017^{* * *}$ & $-0 \cdot 018^{* * *}$ & $-0.019^{* * *}$ & $-0 \cdot 014^{* * *}$ & $-0.014^{* * *}$ & $-0 \cdot 015^{* * *}$ \\
\hline & {$[0 \cdot 004]$} & {$[0 \cdot 004]$} & {$[0 \cdot 004]$} & {$[0 \cdot 004]$} & {$[0 \cdot 004]$} & {$[0 \cdot 004]$} \\
\hline \multirow[t]{2}{*}{ Height of child $(\mathrm{cm})$} & $0.009^{* * *}$ & $0.009^{* * *}$ & $0.009^{* * *}$ & 0.003 & 0.003 & 0.004 \\
\hline & {$[0 \cdot 003]$} & {$[0 \cdot 003]$} & {$[0 \cdot 003]$} & {$[0 \cdot 003]$} & {$[0 \cdot 003]$} & {$[0 \cdot 003]$} \\
\hline \multirow[t]{2}{*}{ Age of mother (years) } & $0 \cdot 010^{* *}$ & $0 \cdot 011^{* *}$ & $0 \cdot 011^{* *}$ & $0 \cdot 009^{*}$ & $0 \cdot 009^{*}$ & 0.008 \\
\hline & {$[0 \cdot 005]$} & {$[0 \cdot 005]$} & {$[0 \cdot 005]$} & {$[0 \cdot 005]$} & {$[0 \cdot 005]$} & {$[0 \cdot 005]$} \\
\hline \multirow[t]{2}{*}{ Age of father (years) } & -0.007 & -0.007 & $-0.007^{*}$ & 0.005 & 0.003 & 0.003 \\
\hline & [0.004] & [0.004] & [0.004] & {$[0 \cdot 005]$} & {$[0 \cdot 005]$} & {$[0.005]$} \\
\hline \multirow[t]{2}{*}{ Height of mother $(\mathrm{cm})$} & -0.002 & -0.002 & -0.002 & $-0 \cdot 000$ & -0.001 & $-0 \cdot 001$ \\
\hline & {$[0 \cdot 003]$} & {$[0 \cdot 003]$} & {$[0 \cdot 003]$} & {$[0 \cdot 003]$} & {$[0 \cdot 003]$} & [0.003] \\
\hline \multirow[t]{2}{*}{ Height of father $(\mathrm{cm})$} & -0.003 & -0.003 & -0.003 & 0.004 & 0.003 & 0.003 \\
\hline & {$[0.003]$} & {$[0 \cdot 003]$} & {$[0 \cdot 003]$} & {$[0 \cdot 003]$} & {$[0 \cdot 003]$} & {$[0 \cdot 003]$} \\
\hline \multirow[t]{2}{*}{ Constant } & -0.461 & -0.427 & $-1.408^{* *}$ & $-1.496^{* *}$ & $-1 \cdot 319^{* *}$ & $-2 \cdot 234^{* * *}$ \\
\hline & {$[0 \cdot 616]$} & {$[0 \cdot 615]$} & {$[0 \cdot 676]$} & {$[0 \cdot 640]$} & {$[0 \cdot 635]$} & {$[0 \cdot 692]$} \\
\hline Additional controls & Yes & Yes & Yes & Yes & Yes & Yes \\
\hline Observations & 3333 & 3333 & 3333 & 3250 & 3250 & 3250 \\
\hline$R^{2}$ & $0 \cdot 112$ & $0 \cdot 118$ & $0 \cdot 121$ & $0 \cdot 128$ & $0 \cdot 140$ & $0 \cdot 144$ \\
\hline
\end{tabular}

Notes: The dependent variable in Columns (1) and (2) measures general willingness to take risks on a 11-point scale from 0 (completely unwilling to take risks) to 10 (completely willing to take risks) and is standardized. Explanatory risk variables are also measured on the 11-point scale and are also standardized. Average willingness to take risks in the region (Raumordnungsregion) is based on the full 2004 SOEP sample and excludes the child from calculation of the average. Results in Columns (1) and (3) are taken from Columns (2) and (6) of Table 1 and are shown again for ease of comparison. Coefficients in all columns are OLS estimates. Robust standard errors in brackets allow for clustering at the household level; ***, **, and * indicate significance at $1 \%, 5 \%$, and $10 \%$ level, respectively. Additional controls include gender and age composition of the region and number of residents. All religion information is obtained from the 2003 wave of the SOEP.

drawn among the population of the same region. ${ }^{27}$ The vertical bars indicate the correlation that results from the true mothers and fathers, respectively. Panels (c) and (d) of Figure 3 present similar histograms for trust. The figures illustrate that in all cases the hypothesis that regional af- 


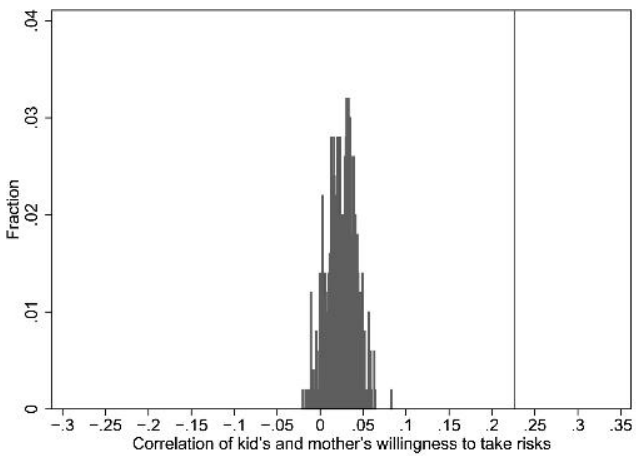

(a) Correlation Random MotherChild: Risk

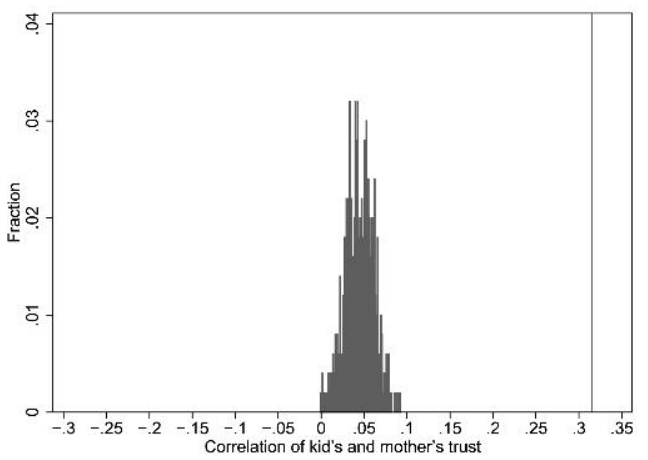

(c) Correlation Random MotherChild: Trust

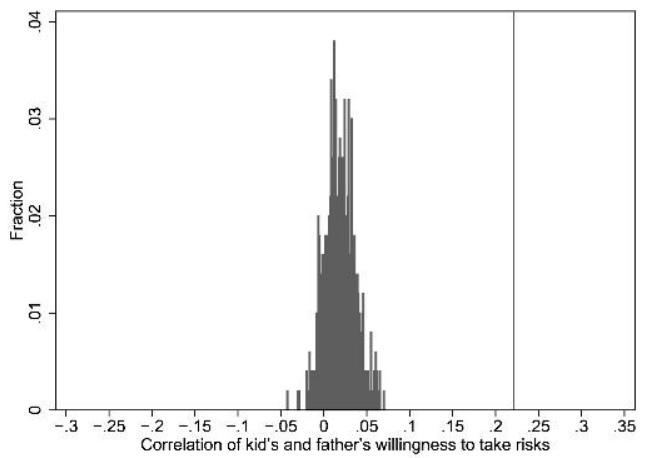

(b) Correlation Random FatherChild: Risk

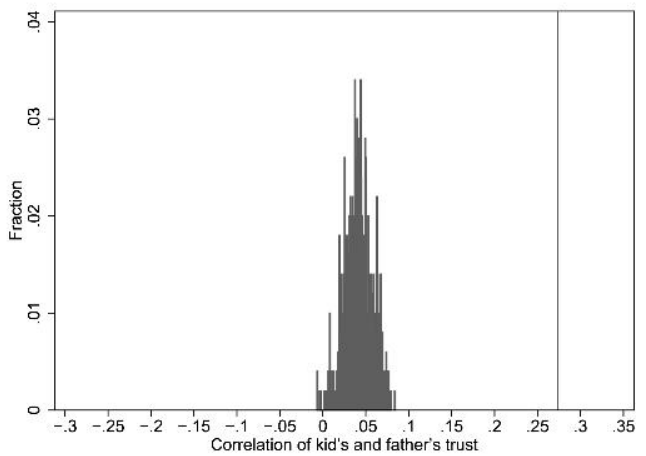

(d) Correlation Random FatherChild: Trust

FIGURE 3

Correlations with randomly assigned parents from same region. The upper diagrams in the figure show the distribution of correlation coefficients of willingness to take risks between children and randomly matched adults. The correlation coefficients are obtained from 500 iterations where each involves randomly matching a child to a parent who lives in the same region as the child's actual parent. The vertical line indicates the correlation coefficient for the risk attitudes of children and their actual parents, as observed in the SOEP data. The bottom diagrams in the figure show similar results for the correlation in the principal component "trust", again based on 500 iterations of random matching within regions. The vertical line indicates the correlation coefficient for the principal component "trust" of children and their actual parents as observed in the SOEP. Note that child-parents pairs who do not currently live in the same region are excluded

filiation drives the positive correlation in attitudes between child and parents is strongly rejected. On the other hand, the correlations with regional attitudes obtained with randomly assigned parents rather than true parents are always positive, consistent with our results above showing an independent role for regions in influencing child attitudes.

\section{ASSORTATIVE MATING OF PARENTS}

We now turn to a third aspect of the transmission process, positive assortative mating. Notably, the previous results are consistent with both mothers and fathers influencing the child, which is a prerequisite for assortative mating to be relevant for child attitudes. 
A priori, the prediction of whether assortative mating should be positive or negative depends on whether these are substitutes or complements in the production of joint utility for the couple (Lam, 1988). For example, to the extent that there are gains to specialization in production, and these different tasks are better suited for different risk attitudes, it could be optimal to have one member of the couple who is risk-seeking and another who is risk averse. ${ }^{28}$ On the other hand, given that we find that both parents influence child attitudes, attitude transmission models predict positive assortative mating because parents who have a preference for children with attitudes similar to their own have an incentive to seek out partners with similar risk and trust attitudes.

Table 7 presents estimation results for the correlation of attitudes among couples. In Columns (1)-(3), the sample includes all cohabiting married and non-married couples for whom we have non-missing values on risk attitudes and other relevant regressors; the sample in Columns (4)(6) only includes parents for whom the child's risk attitude is observed, i.e. for parents in the sample analysed in Section 3.1. In Panel A, the dependent variable is the willingness of the female spouse (partner) to take risks on the 11-point scale. The results show a strong and positive relationship of female spouse's risk attitudes with the risk attitudes of the male spouse. The effect remains positive and significant when controlling for exogenous and other controls in Columns (2) and (3) or (5) and (6), respectively. The usual effects of age and height on risk attitudes remain significant. Evidence of positive assortative mating on risk attitudes is not confined to the question about risk taking in general. We find a similarly significant and positive correlation if we use any of the five context-specific risk questions to measure female and male spouse's risk attitudes. Using female spouse's responses to the hypothetical lottery question, we also find a strong positive relationship such that if the male spouse invests 1000 Euros more, the female spouse invests an additional 300 Euros. Panel B of Table 7 investigates whether there is a significant correlation between couples in terms of trust and whether the correlation is positive as in the case of risk attitudes. For our usual specifications, we find a strong positive relationship between the trust principal component of the female spouse and the trust principal component of the male spouse, indicating the presence of positive assortative mating along the dimension of trust.

To check whether endogeneity of female spouse's attitudes could bias the estimated correlation, we investigated the within-couple correlation in attitudes, instrumenting for one spouses' attitudes by the attitudes of the spouse's parents (mother and father). The relevant sample is thus all couples for whom we observe attitudes of at least one spouse's parents. The dependent variable is the attitude of the spouse for whom we do not observe parental attitudes, regressed on the instrumented attitude of the other spouse. The maintained assumption is that parental attitudes are exogenous to the attitudes of the child's spouse, other than through the channel of the child's attitudes (and potentially other child characteristics, but these are included as controls). In this case, first-stage $F$-tests are typically well above 10 , and the IV estimate of the correlation between couples is almost twice as large, for both risk and trust attitudes. This suggests that if anything the coefficients on spouse's attitudes in Table 7 may be biased downwards.

As another robustness check, we use the same specification as in the Columns (2) and (5) of Table 7 but restrict the sample to couples who got married during the current or previous year. We find that the within-couple correlation is still significant and positive and almost as large as for the full sample of couples: the coefficient on male spouse's risk attitudes is 0.24 and the coefficient for trust attitudes is $0 \cdot 34$, both significant at the $5 \%$ level. This helps to rule out the

28. See Chiappori and Reny (2006) for a theoretical model in which negative assortative mating arises in equilibrium. 
TABLE 7

The relationship between female and male spouses' attitudes

\begin{tabular}{|c|c|c|c|c|c|c|}
\hline \multicolumn{7}{|c|}{ Panel A } \\
\hline \multirow[b]{3}{*}{ Dependent variable } & \multicolumn{6}{|c|}{ Willingness to take risks in general: female spouse } \\
\hline & \multicolumn{3}{|c|}{ Full sample } & \multicolumn{3}{|c|}{ Parents in sample } \\
\hline & (1) & (2) & (3) & (4) & (5) & $(6)$ \\
\hline \multicolumn{7}{|l|}{ Willingness to take risks } \\
\hline Male partner (standardized) & $\begin{array}{l}0 \cdot 341^{* * *} \\
{[0 \cdot 012]}\end{array}$ & $\begin{array}{c}0 \cdot 312^{* * *} \\
{[0 \cdot 012]}\end{array}$ & $\begin{array}{c}0 \cdot 272^{* * *} \\
{[0 \cdot 013]}\end{array}$ & $\begin{array}{c}0 \cdot 388^{* * *} \\
{[0 \cdot 019]}\end{array}$ & $\begin{array}{l}0.358^{* * *} \\
{[0 \cdot 020]}\end{array}$ & $\begin{array}{l}0.262^{* * *} \\
{[0.021]}\end{array}$ \\
\hline \multicolumn{7}{|l|}{ Additional controls } \\
\hline Age, height & No & Yes & Yes & No & Yes & Yes \\
\hline Other controls & No & No & Yes & No & No & Yes \\
\hline Observations & 7278 & 7271 & 6677 & 3337 & 3337 & 3112 \\
\hline$R^{2}$ & $0 \cdot 116$ & $0 \cdot 130$ & $0 \cdot 190$ & $0 \cdot 151$ & $0 \cdot 166$ & $0 \cdot 297$ \\
\hline \multicolumn{7}{|c|}{ Panel B } \\
\hline & \multicolumn{6}{|c|}{ Trust (principal component): female spouse } \\
\hline & \multicolumn{3}{|c|}{ Full sample } & \multicolumn{3}{|c|}{ Parents in sample } \\
\hline Dependent variable & $(1)$ & $(2)$ & $(3)$ & $(4)$ & $(5)$ & $(6)$ \\
\hline Trust: male partner (standardized) & $\begin{array}{l}0.482^{* * *} \\
{[0 \cdot 012]}\end{array}$ & $\begin{array}{l}0 \cdot 477^{* * *} \\
{[0 \cdot 012]}\end{array}$ & $\begin{array}{l}0 \cdot 412^{* * *} \\
{[0 \cdot 013]}\end{array}$ & $\begin{array}{l}0.477^{* * *} \\
{[0 \cdot 020]}\end{array}$ & $\begin{array}{l}0 \cdot 472^{* * *} \\
{[0 \cdot 021]}\end{array}$ & $\begin{array}{l}0.411^{* * *} \\
{[0.022]}\end{array}$ \\
\hline Additional controls & & & & & & \\
\hline Age, height & No & Yes & Yes & No & Yes & Yes \\
\hline Other controls & No & No & Yes & No & No & Yes \\
\hline Observations & 6967 & 6953 & 6408 & 3301 & 3292 & 2868 \\
\hline$R^{2}$ & $0 \cdot 232$ & $0 \cdot 234$ & $0 \cdot 288$ & $0 \cdot 227$ & $0 \cdot 234$ & $0 \cdot 340$ \\
\hline
\end{tabular}

Notes: The dependent variable in Panel A measures general willingness to take risk on a 11-point scale from 0 (completely unwilling to take risks) to 10 (completely willing to take risks) and is standardized. Explanatory risk variables are also coded on the 11-point scale and standardized. The dependent variable in Panel B measures trust as the principal component obtained from agreement with three statements regarding trust (general trust, reliance on others, need for caution in dealing with strangers) measured on a four-point scale. The measures are standardized. Risk and trust variables for male partners are obtained by a similar procedure and are standardized as well. The sample in Columns (1)-(3) is restricted to cohabiting married and non-married couples, and the sample in Columns (4)-(6) is restricted to mothers and fathers of children for which risk and trust measures, respectively, are observed. Coefficients in all columns are OLS estimates. Robust standard errors in brackets allow for clustering at the household level; ***, **, and * indicate significance at $1 \%, 5 \%$, and $10 \%$ level, respectively. Additional other controls in Columns (3) and (6) include years of schooling of female and male partner; corresponding indicator variables for missing schooling information; indicator variables for characteristics of the residence of youth before the age of 16, for both partners (big city, city, countryside, missing; the reference category is small town); indicator variables for religion of both partners (catholic, protestant, other non-Christian, no religious affiliation, missing religion; the reference category is other Christian), gross annual household income for both partners, subjective health status of both partners (five response categories), and fixed effects for region (Raumordnungsregion) and 17 nationality-ethnicity dummies (reference category is German) of female partner. All religion information is obtained from the 2003 wave of the SOEP.

possibility that people who get married subsequently develop similar attitudes, as opposed to similarity in attitudes causing people to get married.

\section{FURTHER EVIDENCE ON MECHANISMS OF SOCIALIZATION}

Models of cultural transmission assume that parents pass on their attitudes through a process of socialization, without ruling out that non-social, or genetic, mechanisms could play a role as 
well. Several of our findings so far indicate that transmission does, indeed, involve socialization and is not a purely genetic process. For example, we have shown that children reproduce the specific variation in attitudes across contexts observed in the parents, which is hard to explain with genetics and indicates that socialization is a rather fine-tuned process. The tendency for mothers to be more important than fathers for trust transmission would not be expected based on genetic transmission but indicates a process of socialization in which parents have unequal impacts on child attitudes. The impact of regional attitudes suggests an important role for genetically unrelated individuals as role models and is thus a clear indicator of socialization.

In this section, we investigate the socialization process in more detail. Thus far, we have focused on testing for the three main aspects of socialization featured in the theory. In this section, we delve deeper and investigate the empirical support for more specific assumptions about the nature of the socialization production function. These specify particular parental characteristics, or aspects of family structures, that create costs or obstacles to socialization and thus tend to lead to a weaker relationship between parent and child attitudes but should be irrelevant from the perspective of genetic transmission. Results from this analysis are presented in Table 1: each pair of columns contrasts the intergenerational transmission across different subsamples to shed light on mechanisms for socialization. Significance tests for equality of coefficients across equations, reported in the text, are based on the appropriate chi-squared statistics.

We begin by investigating how similarity of the parents affects strength of transmission. The model of Bisin and Verdier (2000) explicitly assumes that more dissimilar parents have a less efficient technology for socializing the child. This assumption helps generate the prediction that individuals engage in positive assortative mating because it gives them an incentive to do so. One reason why socialization might be less powerful with heterogeneous parents is if receiving conflicting signals from the two parents leads the child to look elsewhere for guidance. Alternatively, this could arise because individuals who plan to exert high levels of effort in socializing their child are also willing to search especially hard for a similar mate. We run separate regressions relating child attitudes to parental attitudes, for children with relatively homogeneous parents (absolute difference between parental attitudes of less than 1 S.D.) and children with relatively heterogeneous parents (difference of more than 1 S.D.). As shown in Columns (1) and (2) of Table 1, relatively homogeneous parents consistently have a stronger impact on the child's risk attitudes than heterogeneous parents, on the order of four percentage points for mothers and eight percentage points for fathers. ${ }^{29}$ These differences across samples are only marginally significant, for the case of fathers' attitudes. Combining parental attitudes by taking their average, however, the difference between homogeneous and heterogeneous couples becomes statistically significant at the 5\% level $(p<0 \cdot 049) .{ }^{30}$ For trust attitudes, transmission is also typically weaker for heterogeneous parents, but differences are not statistically significant, even when considering the combined (averaged) influence of the parents. Thus, the data do provide some support for the assumption that parents have a weaker impact on the child when their mate is dissimilar, although this is only precisely estimated for risk attitudes.

We also address the question of how parental characteristics affect strength of transmission from a different angle, by looking at single-parent households. Bisin and Verdier (2000) assume that single-parent households are less effective in socializing the child than homogeneous parent couples. This generates a tendency in their model for an individual to engage in positively assortative mating rather than mating with a randomly chosen individual and then passing on attitudes

29. We use specifications corresponding to Column (2), and Column (6), of Table 1.

30. This result is not reported in the table. The greater significance when using the average of parental attitudes is consistent with a reduction in measurement error for the combined effect of the parents. Results are similar if we include all controls as in Column (3) of Table 1 , although significance drops slightly $(p<0.051)$. 


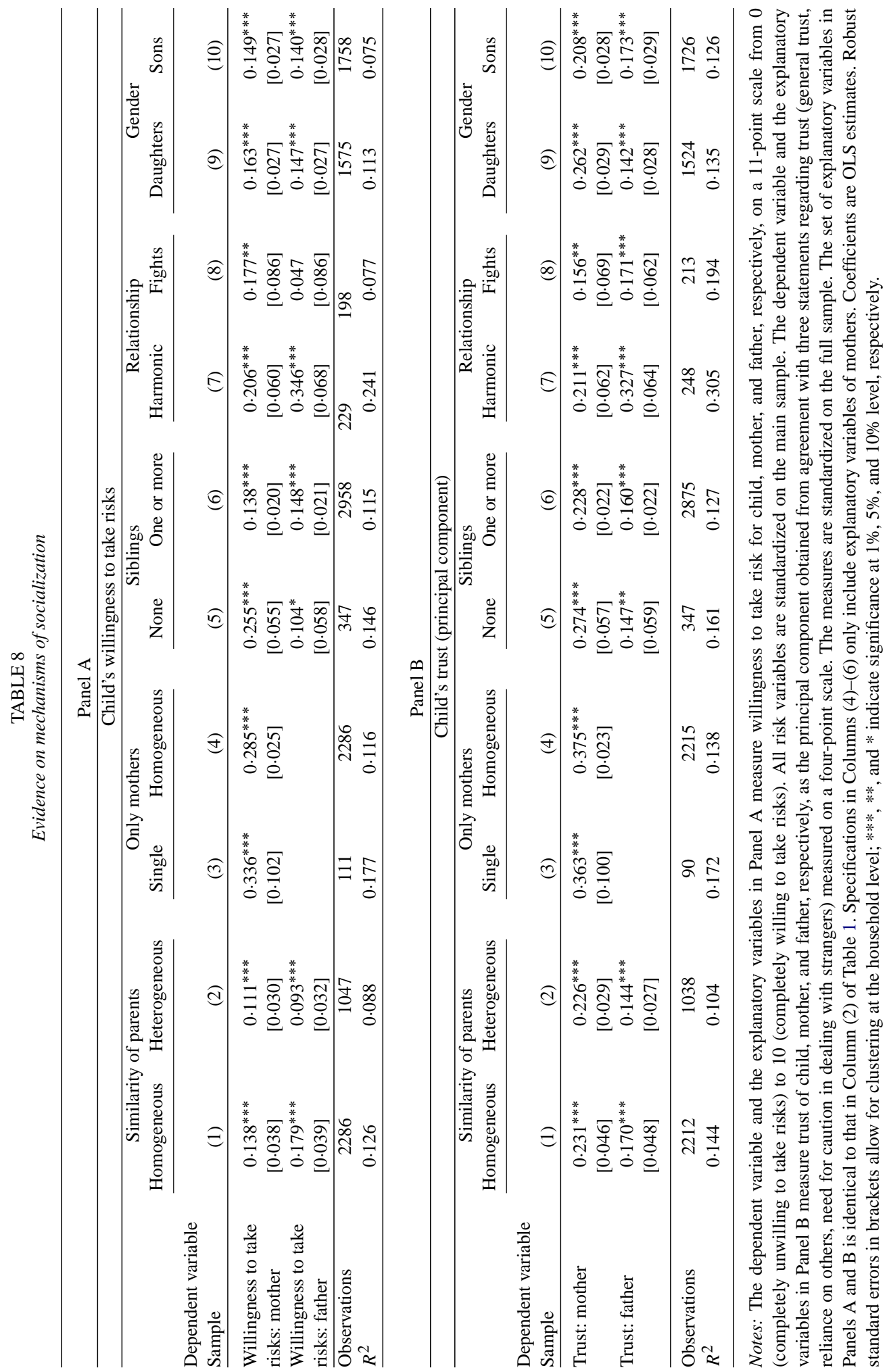


without interference from the mate by raising the child as a single parent. This assumption could be true, e.g. because a single parent has sole responsibility for running the household and has limited time to devote to socializing the child. Alternatively, however, it seems plausible that single parents could have a rather strong influence on the child, as the sole role model. Thus, it is interesting to investigate this comparison empirically. As there are only very few single fathers in the sample, we focus on single mothers and identify children who lived for some of the first 15 years of life with their mother but not their father. We estimate the relationship between child and parental attitudes for children who lived with a single mother and compare to the same relationship estimated for the sample of children with relatively homogeneous parental couples. ${ }^{31}$ Comparing Columns (3) and (4), we find that children with single mothers are influenced essentially to the same extent as children with a mothers in homogeneous parent couples, for both risk and trust attitudes ( $p<0.63$ for risk; $p<0.82$ for trust). Thus, even in the best-case scenario for a married mother to pass on her attitudes, namely in a homogeneous couple, there does not seem to be an advantage relative to being a single mother. Interestingly, children with a single mother are even more strongly influenced than children with a mother in a heterogeneous parent couple (not shown); this latter comparison is statistically significant for risk attitudes $(p<0.02)$ but not for trust attitudes $(p<0 \cdot 20)$. Thus, unlike in the model of Bisin and Verdier (2000), mating randomly and then staying a single mother might be a viable alternative strategy to positively assortative marriage, for a mother who wants to pass on her own attitudes to the child. This would require the additional assumption, however, that fathers are disadvantaged in some way in getting custody of the child or that they are less interested in socializing the child. Otherwise, fathers would resist this strategy on the part of the mother. Both assumptions are moderately plausible, raising the intriguing possibility that single motherhood could sometimes be partly strategic on the part of mothers, as an effort to avoid the influence of a dissimilar spouse.

Another factor that could affect socialization is the number of children in the family. For example, because time is limited, parents may be able to devote less one-on-one time to a child as the number of children increases, reducing the strength of socialization. In other words, there may be a quality versus quantity trade-off in the number of children (e.g. Becker and Lewis, 1973 ) but where quality is in terms of success in socialization. In terms of the theory, a greater number of children could correspond to a larger $\beta$ parameter in the cost function for direct socialization. We do find some indication for this effect, in the case of mother's risk attitudes. As shown in Columns (5) and (6), the correlation between mother and child risk attitudes is substantially larger for single children compared to children with siblings, and the difference is statistically significant $(p<0 \cdot 05)$. For trust, number of siblings does not affect the transmission process for either mothers or fathers, providing an indication that the processes of socialization for risk and trust differ in important ways. ${ }^{32}$

Parental ability to socialize the child could also depend on the quality of the relationship

31. To assess the total impact of the mother in a homogeneous couple, we regress the child's attitude on the mother's attitudes and controls, excluding the father's attitude. The coefficient on mother's attitude then incorporates both the mother's direct influence and the reinforcing effect due to positive assortative mating. This is the appropriate comparison to assess which family choice would allow the mother a better chance of passing on her attitudes to the child.

32. In a related analysis (not reported), we examined how birth order affects the strength of transmission. We find a significant effect: children who are born later are more dissimilar to the parents in terms of mother's and father's risk attitudes. We find a similar pattern for birth order and the impact of father's trust. This is consistent with first-born children being more influenced, due to time in the home before siblings arrive. By contrast, there is only a very small (and slightly positive) impact of birth order on the correlation with the mother's trust. Mothers thus affect trust of all children equally regardless of birth order, consistent with the general tendency for mothers to have a stronger impact on the child in the case of trust. 
between parents and children. For a subsample of children in our data, we have information on whether children frequently "fought" with their parents when growing up. As shown in Columns (7) and (8), for both risk and trust attitudes the correlation between parental and child attitudes is much larger (by roughly 20 percentage points) for families that seldom fought compared to those who often fought. Interestingly, the effect is larger and is statistically significant $(p<0.01$ for risk; $p<0.10$ for trust), for fathers. This is consistent with a poor relationship interfering with socialization, in particular for transmission from fathers; the influence of the mother is relatively less affected by the quality of the relationship between child and parents. One caveat is that, in this case, some of the causality might run the other way, i.e. families could conceivably fight because parents and children are different in terms of risk and trust attitudes.

To shed further light on the socialization process, we also investigate whether transmission of risk and trust attitudes interacts with gender of the child. It could potentially be the case that the gender of the child affects the socialization ability of mothers versus fathers if, e.g. mothers are more important role models for daughters and fathers for sons. On the other hand, it is not clear that this needs to be the case. In Columns (9) and (10), we report results for sons and daughters, respectively. We find that the impacts of mother and father are not significantly different, depending on the gender of the child. Thus, there is little support for the gender-specific role-model hypothesis, for risk and trust attitudes.

Finally, if transmission of attitudes reflects socialization, one might expect the economic success, or subjective well-being, of parents to play a role in the strength of transmission. Most models of cultural transmission assume that parents are altruistic towards the child. Thus, parents might potentially try to prevent children from adopting attitudes that proved counter-productive for the parents. Children might also be less open to adopting attitudes of parents when parents are unsuccessful. We find (in unreported regressions) that fathers with a higher subjective wellbeing have a greater impact on the child ( $p<0.03$ for trust; $p<0.11$ for risk). Interestingly, the interaction term with mother's subjective well-being is essentially zero and far from statistically significant. Thus, individuals end up being like their mother regardless of the mother's subjective well-being.

In summary, transmission of risk and trust attitudes shows clear signs of occurring through a process of socialization. Socialization appears to depend on a complex interplay of parental characteristics and different aspects of family structure. The results are informative for theoretical assumptions about the nature of the socialization production function. They are also potentially relevant for policy interventions focused on influencing non-cognitive skills in childhood (Heckman, 2006) as they indicate that fundamental attitudes are malleable and point to specific factors that matter for the influence of family environment. The results in this section also contribute to a recent debate in psychology on whether parents socialize children at all. Based on the behavioural genetics method of using siblings to decompose transmission into heritability versus parent socialization, it has been argued that the influence of parents on child personality is almost solely genetic (Harris, 1995) and that socialization occurs only through peers. But such decompositions rely on very strong assumptions about separability of genetic and environmental influences (Cunha and Heckman, 2009). Relatedly, studies that use identical twin siblings to identify genetic influences are problematic due to evidence that identical twins are not actually genetically identical into adulthood because of environment-gene interactions (e.g. Fraga et al., 2005). Our results show that the strength of transmission from parents to children varies with within-family factors that could be expected to play a role in socialization but should be irrelevant from a genetic perspective. While this leaves open the relative quantitative contributions of genetics versus socialization, it casts doubt on the claim that parents are unable to socialize their children and that all socialization occurs through peer effects. 


\section{ECONOMIC IMPLICATIONS}

Attitude transmission is ultimately of importance to economics to the extent that it explains economic outcomes. In this final results section, we provide empirical evidence on the economic significance of attitude transmission. Our approach is to first empirically establish the impact of risk and trust attitudes on various economic outcomes that involve risk and trust. We then combine these estimates with our estimates of the intergenerational correlation in attitudes to assess the implications of parental attitudes for child outcomes through the channel of attitude transmission.

We consider a range of risky activities in various contexts. In particular, we study investing in stocks, participation in active sports, self-employment, and smoking. We relate the propensity to engage in each of these activities to individual risk attitudes in the most appropriate specific context (see Table 3). Our outcome regressions use the entire sample for the 2004 wave of the SOEP to provide the most representative estimates of how attitudes affect economic outcomes. We include controls for exogenous characteristics, as in Column (1) of Table 2. All outcomes we consider are highly significantly related to risk attitudes, at the $1 \%$ level. ${ }^{33}$ We then scale the coefficients relating risk attitudes to outcomes by the strength of intergenerational transmission for that particular context-specific attitude measure. For example, a 1 S.D. increase in the mother's and father's willingness to take risks in the context of career matters has a total impact of 0.324 S.D. increase in the child's willingness to take risks (see Table 3). Based on our estimates from the outcome regressions, this implies a $19 \%$ increase in the probability of the child choosing the risky occupation of self-employment $(p<0 \cdot 01) .{ }^{34}$ Relative to other demographic determinants, this effect is non-trivial. For example, controlling for risk attitudes, being male increases the probability of being self-employed by only about $10 \%$. Following a similar procedure, we find that increasing the parents' willingnesses to take risks by 1 S.D. causes a $10 \%$ increase in the probability of holding stocks $(p<0.01)$, an $8 \%$ increase in the probability of playing active sports $(p<0.01)$, and a $6 \%$ increase in the probability of being a smoker $(p<0.01)$. Risk attitudes are also significantly correlated with fundamental outcomes like income, wealth, and education, although in this case causality is less clear. For example, a 1 S.D. increase in parental general risk attitudes is associated with a $3 \%$ increase in child household income $(p<0 \cdot 01)$, a $6 \%$ increase in the child's household wealth $(p<0 \cdot 01)$, and about one additional month of educational attainment $(p<0 \cdot 01)$. In summary, the transmission of risk attitudes has a non-trivial impact on a wide range of individual behaviours such that the cumulative effect on the child's economic situation seems substantial.

Trust is also related to a variety of outcomes. As trust is thought to be important for sustaining relationships, we investigate the relationship between trust and number of close friends and the probability of being in an employment relationship. We also investigate whether trust is related to political affiliation; left-wing and conservative political outlooks are often characterized as differing in beliefs about the essential goodness of individuals, with liberals being more trusting. We again use the full sample from the 2004 wave of the SOEP to relate outcomes to attitudes and then combine these estimates with estimates of the intergenerational transmission of trust attitudes. ${ }^{35}$ All the outcomes we consider are significantly related to trust attitudes at the $1 \%$

33. Results for the outcome regressions are available upon request.

34. The coefficient relating outcomes to risk attitudes is multiplied by the sum of the attitude transmission coefficients for mother and father. Standard errors for this product are calculated using bootstrapping, with 1000 repetitions (results are essentially identical using different numbers of draws). The sample of children with information on parental risk attitudes, used to estimate attitude transmission coefficients, is a subsample of the data set used to estimate the outcome regressions. Bootstrapping was done in a stratified way, drawing with replacement from the child subsample.

35. Trust attitudes are taken from the 2003 wave. We use the 2004 wave so as to have comparable information on 
level. ${ }^{36}$ We calculate that a 1 S.D. increase in mother's and father's trust is associated with a $1 \%$ increase in the child's number of close friends $(p<0.01)$ and a $11 \%$ increase in the probability of being employed $(p<0 \cdot 01)$. This change in parental trust is also associated with a substantially higher probability of voting for the two relatively left-wing parties in Germany: $8 \%$ and 24\% for the SPD (Social Democrats) and Green Party, respectively $(p<0.01 ; p<$ $0 \cdot 01)$. Trust is also significantly correlated with income and education. A 1 S.D. increase in parents' trust attitudes is associated with a 9\% increase in household income for the child ( $p<$ $0.01)$, and about 1.5 months of additional schooling $(p<0.01)$. Thus, similar to risk attitudes, intergenerational transmission of trust implies an effect on a wide variety of child behaviours.

Overall, the picture that emerges is one in which attitude transmission matters by shifting the child's disposition towards all types of decisions involving risk and trust. The impact on individual behaviours is non-trivial but is far from deterministic. This could also partly reflect measurement error in attitudes, which biases the relationship between attitudes and specific behaviours downwards. It also suggests that other factors, such as institutions, may play an important role in explaining the persistence of any specific behaviour over generations. On the other hand, the total effect of transmission of risk attitudes seems large because of the extensive set of behaviours that are influenced.

\section{CONCLUSION}

By assuming that economically relevant attitudes are transmitted across generations, recent theories have been able to rationalize a wide range of important behaviours and outcomes. A key element of these new explanations, however, has been unobserved, namely the process of attitude transmission itself. This paper provides empirical evidence on three different channels for attitude transmission emphasized in the literature: (1) transmission of attitudes from parents to children; (2) an influence of other role models in the environment on child attitudes, in addition to parents; and (3) positive assortative mating of parents, which tends to reinforce the impact of parents on the child. The findings indicate that all three mechanisms matter for child attitudes, which provides an empirical underpinning for the attitude transmission approach and helps open the black box of where fundamental economic attitudes come from.

Evidence of attitude transmission is relevant for other literatures as well. A large body of evidence has shown strong persistence in economic outcomes such as income, education, and asset holdings across generations (for a recent survey, see Björklund, 2007). Although doubtless many factors play a role at the micro level (such as direct transfers of resources), transmission of attitudes provides an additional channel; children may end up with similar outcomes partly because they have similar attitudes to parents and thus make the same patterns of choices. Another application is to the literature on assortative mating, where there is evidence of correlated behaviours between married individuals, e.g. in terms of smoking or educational choice (see, e.g. Fernández, Gunner and Knowles, 2005). Positive assortative mating on the basis of fundamental attitudes is one possible explanation for why couples exhibit similar behaviours. The finding that regional attitudes affect child attitudes is also relevant for literatures on social interaction and neighbourhood effects. Specifically, regional contagion of risk preference and trust provide evidence for two of the three channels for social interaction effects hypothesized by Manski (2000), namely social interaction effects working through the channel of preferences and through the channel of expectations. These mechanisms can in turn help explain evidence of neighbourhood effects. For example, regional attitude transmission helps explain the find-

control variables to our results on risk attitudes.

36. Results are available upon request. 
ing that similarity in various economic behaviours is reinforced for ethnic groups that tend to cluster in the same geographic area (Fernández and Fogli, 2005) and the finding that an individual's trust is related to trust in the country of ancestry (Guiso, Sapienza and Zingales, 2006). Transmission of attitudes, particularly regarding risk, is also potentially relevant for explaining correlations between adolescents' risky behaviours (e.g. drug use and crime) and behaviours of other role models in the local environment (see, e.g. Case and Katz, 1991; Glaeser, Sacerdote and Scheinkman, 1996).

An important direction for future research is investigating the three-fold channels for transmission of other economically relevant attitudes. For example, impatience is a prime candidate as recent theoretical work hypothesizes that parents deliberately invest in a particular discount rate for the child (Doepke and Zilibotti, 2005, 2008). Another candidate is reciprocity, the tendency to respond in-kind to hostile or kind actions by others. We have done some initial analysis of transmission of reciprocity using survey questions in the SOEP, which ask about willingness to return favours of those who have been kind and punish those who were unkind. ${ }^{37}$ We find that, indeed, reciprocal inclinations are strongly positively correlated between child and parent: $0 \cdot 167$ (mother) and 0.179 (father) for positive reciprocity (willingness to return a favour); 0.208 (mother) and $0 \cdot 197$ (father) for negative reciprocity (willingness to punish unkindness). Transmission of reciprocity is potentially very important because the degree of reciprocity in a society is a crucial component of social capital, e.g. negative reciprocity may help sustain informal sanctions of norm violators (Fehr and Gächter, 2000; Bowles and Gintis, 2002; Dohmen et al., 2009). These findings call for further research on the nature and extent of attitude transmission to understand the full implications for child economic outcomes.

Acknowledgment. The authors are grateful to the editor, Kjetil Storesletten, three referees, as well as participants at numerous seminars and conferences for helpful comments and suggestions, in particular Gary Becker, Alberto Bisin, Jim Heckman, Ernst Fehr, Raquel Fernandez, Simon Gächter, Steffen Huck, John List, Ulrike Malmendier, Jürgen Schupp, Gert Wagner, and Fabrizio Zilibotti. The usual disclaimer applies. Financial support by the European Research Council (Starting Grant), the German Science Foundation (DFG) through SFB/TR 15, the Volkswagen Foundation, IZA, Bonn, and the Netherlands Organization for Scientific Research (NWO) is gratefully acknowledged.

\section{Supplementary Data}

Supplementary data are available at Review of Economic Studies online

\section{REFERENCES}

BARSKY, R. B., JUSTER, T. F., KIMBALL, M. S.and SHAPIRO, M. D. (1997), "Preference Parameters and Individual Heterogeneity: An Experimental Approach in the Health and Retirement Study", Quarterly Journal of Economics, 112, 537-579.

BECKER, G. S. and LEWIS, H. (1973), "On the Interaction Between the Quantity and Quality of Children”, Journal of Political Economy, 81, S279-S288.

BERG, J., DICKHAUT, J. and MCCABE, K. (1995), “Trust, Reciprocity and Social History”, Games and Economic Behaviour, 10, 122-142.

BISIN, A., TOPA, G. and VERDIER, T. (2004), "Religious Intermarriage and Socialization in the United States", Journal of Political Economy, 112, 615-664.

BISIN, A. and VERDIER, T. (2000), "'Beyond the Melting Pot': Cultural Transmission, Marriage, and the Evolution of Ethnic and Religious Traits". Quarterly Journal of Economics, 115, 955-988.

BJÖRKLUND, A. (2007). "Family Background and Outcomes Later in Life: A (Partial and Personal) Survey of Recent Research Using Swedish Register Data" (Working Paper No. 4/2007, SOFI).

BONIN, H., DOHMEN, T., FALK, A., HUFFMAN, D. and SUNDE, U. (2007), "Cross-sectional Earnings Risk and Occupational Sorting: The Role of Risk Attitudes”, Labour Economics, 14, 926-937.

37. For a description of the questions, and evidence on the determinants and consequences of reciprocity, see Dohmen et al. (2009). 
BORGHANS, L., DUCKWORTH, A., HECKMAN, J. and TER WEEL, B. (2008), "The Economics and Psychology of Personality Traits", Journal of Human Resources, 43, 972-1059.

BORGHANS, L., MEIJERS, H. and TER WEEL, B. (2008), "The Role of Noncognitive Skills in Explaining Cognitive Test Scores", Economic Inquiry, 46, 2-12.

BOWLES, S. and GINTIS, H. (2002), "Social Capital and Community Governance”, Economic Journal, 112, F419F436.

CAMERER, C. and HOGARTH, R. (1999), "The Effects of Financial Incentives in Experiments: A Review and CapitalLabor-Production Framework", Journal of Risk and Uncertainty, 19, 7-42.

CASE, A. and KATZ, L. (1991), "The Company You Keep: The Effects of Family and Neighborhoods on Disadvantaged Youth" (Working Paper No. 3705, NBER).

CHARLES, K. K. and HURST, E. (2003), "The Correlation of Wealth Across Generations", Journal of Political Economy, 111, 1155-1182.

CHIAPPORI, P.-A. and RENY, P. (2006), "Matching to Share Risk" (Working Paper, Columbia University).

CUNHA, F. and HECKMAN, J. (2009), "The Economics and Psychology of Inequality and Human Development" (Discussion Paper No. 4001, IZA).

DOEPKE, M. and ZILIBOTTI, F. (2005), "Social Class and the Spirit of Capitalism”, Journal of the European Economic Association, 3, 516-524.

DOEPKE, M. and ZILIBOTTI, F. (2008), "Patience Capital, Occupational Choice, and the Spirit of Capitalism”, Quarterly Journal of Economics, 123, 747-793.

DOHMEN, T., FALK, A., HUFFMAN, D. and SUNDE, U. (2008), "Representative Trust and Reciprocity: Prevalence and Determinants", Economic Inquiry, 46, 84-90.

DOHMEN, T., FALK, A., HUFFMAN, D. and SUNDE, U. (2009), "Homo Reciprocans: Survey Evidence on Prevalence, Behavior and Success", Economic Journal, 119, 592-612.

DOHMEN, T., FALK, A., HUFFMAN, D., SUNDE, U., SCHUPP, J. and WAGNER, W. (2011), "Individual Risk Attitudes: Measurement, Determinants and Behavioral Consequences", Journal of the European Economic Association, 9, 522-550.

ERMISCH, J. F., FRANCESCONI, M. and SIEDLER, T. (2006), "Intergenerational Mobility and Marital Sorting", Economic Journal, 116, 659-679.

FALK, A. and ZEHNDER, C. (2007), "Discrimination and In-group Favoritism in a Citywide Trust Experiment" (Discussion Paper No. 2765, IZA).

FEHR, E., FISCHBACHER, U., ROSENBLADT, B. v., SCHUPP, J. and WAGNER, G. G. (2003), "A Nation-wide Laboratory: Examining Trust and Trustworthiness by Integrating Behavioral Experiments into Representative Surveys" (Mimeo, Institute for Empirical Research in Economics, University of Zurich).

FEHR, E. and GÄCHTER, S. (2000), “Cooperation and Punishment in Public Goods Experiments”, American Economic Review, 90, 980-994.

FERNÁNDEZ, R. (2007), "Culture and Economics", in Durlauf, S. and Blume, L. (eds) New Palgrave Dictionary of Economics, 2nd edn (Basingstoke: Palgrave Macmillan). DOI:10.1057/9780230226203.0346.

FERNÁNDEZ, R. and FOGLI, A. (2005), "Culture: An Empirical Investigation of Beliefs, Work, and Fertility” (Working Paper, New York University).

FERNÁNDEZ, R., GUNNER, N. and KNOWLES, J. (2005), "Love and Money: A Theoretical and Empirical Analysis of Household Sorting and Inequality", Quarterly Journal of Economics, 120, 273-344.

FERNÁNDEZ, R., FOGLI, A. and OLIVETTI, C. (2004), "Mothers and Sons: Preference Formation and Female Labor Force Participation”, Quarterly Journal of Economics, 119, 1249-1299.

FERSHTMAN, C. and GNEEZY, U. (2001), "Discrimination in a Segmented Society: an Experimental Approach", Quarterly Journal of Economics, 116, 351-377.

FOWLER, F. (1988), Survey Research Methods (London: Newbury Park).

FRAGA, M. F., BALleSTAR, E., PAZ, M. F., ROPERO, S., SETIEN, F., BALlESTAR, M. L., HEINE-SUNER, D., CIGUDOSA, J. C., URIOSTE, M., BENITEZ, J., BOIX-CHORNET, M., SANCHEZ-AGUILERA, A., LING, C., CARLSSON, E., POUlSEN, P., VAAG, A., STEPHAN, Z., SPECTOR, T. D., WU, Y. -Z., PLASS, C. and ESTELLER, M et al. (2005), "Epigenetic Differences Arise during the Lifetime of Monozygotic Twins", Proceedings of the National Academy of Sciences, 102, 10604-10609.

GANZEBOOM, H. B. G. and TREIMAN, D. (1996), "Internationally Comparable Measures of Occupational Status for the 1988 International Standard Classification of Occupations", Social Science Research, 25, 201-239.

GLAESER, E. L., LAIBSON, D. I., SCHEINKMAN, J. A. and SOUTTER, C. (2000), "Measuring Trust", Quarterly Journal of Economics, 115, 811-846.

GLAESER, E. L., SACERDOTE, B. and SCHEINKMAN, J. A. (1996), "Crime and Social Interactions", Quarterly Journal of Economics, 111, 507-548.

GUISO, L. and PAIELLA, M. (2001), "Risk-Aversion, Wealth, and Background Risk" (Discussion Paper No. 2728, CEPR).

GUISO, L., SAPIENZA, P. and ZINGALES, L. (2003), "People's Opium? Religion and Economic Attitudes", Journal of Monetary Economics, 50, 225-282.

GUISO, L., SAPIENZA, P. and ZINGALES, L. (2006), “Does Culture Affect Economic Outcomes?”, Journal of Economic Perspectives, 20, 23-48. 


\section{DOHMEN ET AL. TRANSMISSION OF RISK AND TRUST ATTITUDES}

HARRIS, J. (1995), “Where Is the Child's Environment? A Group Socialization Theory of Development”, Psychological Review, 102, 458-489.

HAUK, E. and SAEZ-MARTI, M. (2002), "On the Cultural Transmission of Corruption", Journal of Economic Theory, 107, 311-335.

HECKMAN, J. J. (2006), "Skill Formation and the Economics of Investing in Disadvantaged Children”, Science, 312, 1900-1902.

HEINECK, G. and RIPHAHN, R. (2009), "Intergenerational Transmission of Educational Attainment in Germany The Last Five Decades", Journal of Economics and Statistics, 229, 36-60.

KNACK, S. and KEEFER, P. (1997), "Does Social Capital Have an Economic Payoff? A Cross-country Investigation”, Quarterly Journal of Economics, 112, 1251-1288.

KOSFELD, M., HEINRICHS, M., ZAK, P., FISCHBACHER, U. and FEHR, E. (2005), "Oxcytocin Increases Trust in Humans", Nature, 435, 673-676.

LAM, D. (1988), "Marriage Markets and Assortative mating with Household Public Goods: Theoretical Results and Empirical Implications", Journal of Human Resources, 23, 462-487.

LOEHLIN, J., HORN, J. and WILLERMAN, L. (1981), "Personality Resemblance in Adoptive Families", Behavior Genetics, 11, 309-330.

MANSKI, C. (2000), "Economic Analysis of Social Interactions.”, Journal of Economic Perspectives, 14, 115-136.

MCCLEARY, R. and BARRO, R. (2006), "Religion and Economy", Journal of Economic Perspectives, 20, 49-72.

MULligAN, C. B. (1997), Parental Priorities and Economic Inequality (Chicago: University of Chicago Press).

PUTNAM, R. D., LEONARDI, R. and NANETTI, R. Y. (1994), Making Democracy Work: Civic Traditions in Modern Italy (Princeton: Princeton University Press).

SCHUPP, J. and WAGNER, G. G. (2002), "Maintenance of and Innovation in Long-Term Panel Studies The Case of the German Socio-Economic Panel (GSOEP)”, Allgemeines Statistisches Archiv, 86, 163-175.

SOLON, G. (2002), "Cross-country Differences in Intergenerational Income Mobility”, Journal of Economic Perspectives, 16, 59-66.

TABACHNICK, B. G. and FIDELL, L. S. (2001), Using Multivariate Statistics, 2nd edn (Boston: Allyn and Bacon).

TABELLINI, G. (2005), "Culture and Institutions: Economic Development in the Regions of Europe" (Working Paper No. 1492, CESifo).

TABELLINI, G. (2007), "The Scope of Cooperation: Norms and Incentives” (Mimeo, Bocconi University).

WAGNER, G. G., BURKHAUSER, R. V. and BEHRINGER, F. (1993), "The English Language Public Use File of the German Socio-Economic Panel”, Journal of Human Resources, 28, 429-433.

WEBER, M. (1930), The Protestant Ethic and the Spirit of Capitalism (London: HarperCollins). 